\title{
Vacuum Referred Binding Energies of the Lanthanides in Transition Metal Oxide Compounds
}

\author{
Pieter Dorenbos ${ }^{\mathbf{z}}$ and Edith G. Rogers
}

Delft University of Technology, Faculty of Applied Sciences, Department of Radiation Science and Technology (FAME-LMR), $2629 \mathrm{JB}$ Delft, Netherlands

\begin{abstract}
The electronic level schemes for divalent and trivalent lanthanide ions in rare earth ( $\mathrm{La}, \mathrm{Gd}, \mathrm{Y}, \mathrm{Lu}, \mathrm{Sc})$ vanadate, niobate, tantalate, and in alkaline earth $(\mathrm{Ba}, \mathrm{Sr}, \mathrm{Ca}, \mathrm{Mg})$ titanate, molybdate, and tungstate compounds are presented. Use is made of data from luminescence excitation and absorption spectra of lanthanide (mostly $\mathrm{Eu}^{3+}, \mathrm{Pr}^{3+}$, and $\mathrm{Tb}^{3+}$ ) impurities in those compounds. By means of the chemical shift model, binding energies, relative to the vacuum energy, of electrons in the impurity levels and the host bands are obtained. It reveals clear trends in conduction band and valence band energy with changing size of the rare earth or the alkaline earth ion. The bottom of the conduction band is dominated by $3 \mathrm{~d}, 4 \mathrm{~d}$, or $5 \mathrm{~d}$ orbitals, and it is found that the binding energy at the conduction band bottom tends to decrease with higher orbital number.

(c) 2014 The Electrochemical Society. [DOI: 10.1149/2.0061408jss] All rights reserved.
\end{abstract}

Manuscript submitted May 23, 2014; revised manuscript received June 17, 2014. Published June 30, 2014.

The vanadates, titanates, molybdates, niobates, tungstates, and tantalates are widely used in many areas of applied physics and materials science. $\mathrm{TiO}_{2}$ is famous for its photocatalytic activity used to produce hydrogen in electrochemical cells upon absorption of sunlight. Many other titanates and also vanadates are actively being studied for such applications. ${ }^{1}$ It is then crucial that the electron binding energy $E_{V}$ at the top of the valence band and $E_{C}$ at the bottom of the conduction band lie closely below and above the redox potentials for hydrogen and oxygen production. Lanthanides in transition metal (TM) based compounds can produce very bright luminescence. For bright luminescence to occur, the location of the emitting impurity level relative to $E_{C}$ is important. A location too close to $E_{C}$ will result in poor quantum efficiency or even a total absence of emission because of thermal or autoionization of the excited electron to the conduction band. Whether a lanthanide or a transition metal impurity can trap an electron from the conduction band or a hole from the valence band is also controlled by the impurity level locations in the band gap. ${ }^{2}$ That same location tells us the preferred impurity valence state. ${ }^{3}$ The above examples demonstrate that knowledge on the electronic structure, i.e., the absolute binding energy of the electrons in impurity states, host band states, or molecules, is crucial for our understanding of the performance of materials.

There is an abundance of data on lanthanide spectroscopy covering many thousands of different compounds. Data that can provide information on the location of lanthanide impurity levels relative to the valence and conduction bands of the host compound. Once the location of the $4 \mathrm{f}^{n}$ ground state energy of one particular lanthanide impurity is known, say $\mathrm{Eu}^{2+}$, then it can be predicted for all other divalent lanthanides. This good predictability is caused by the atomic like and well-shielded nature of the inner lanthanide 4 f-orbitals. ${ }^{4}$ Host referred binding energy (HRBE) schemes as for $\mathrm{GdVO}_{4}$ in Fig. 1 where all energies are referred to the top of the valence band, see the righthand energy scale, can be made routinely. The ground state energies of divalent and trivalent lanthanides follow characteristic double zigzag shapes that are to a good approximation invariant with the type of host compound. Recently the chemical shift model was introduced. ${ }^{4}$ It enables us to convert a HRBE scheme into a vacuum referred binding energy (VRBE) scheme, see the left-hand energy scale in Fig. 1. Since its introduction, the model has been applied successfully for many wide band gap compounds. ${ }^{5,6} \mathrm{VRBE}$ means the energy required to extract an electron from the system and to bring it to the vacuum. That electron can be from a host band state or from an impurity ground or excited state. When, for example, an impurity excited state is drawn inside the band gap at two $\mathrm{eV}$ above the top of the valence band it means that it requires $2 \mathrm{eV}$ less energy to extract an electron from that excited state and bring it to the vacuum than to extract an electron from the top of the valence band. As matter of convenience, we will often speak of the VRBE of an electron as if it concerns a single electron. In reality we are always dealing with multi-particle states and systems.

In this work the models and ideas are applied to the following compounds. 1) The rare earth vanadates $\left(\mathrm{REVO}_{4}\right.$ with $\mathrm{RE}=\mathrm{La}$, $\mathrm{Gd}, \mathrm{Y}, \mathrm{Lu}$, or $\mathrm{Sc}), \mathrm{TiO}_{2}$, and the alkaline earth titanates $\left(\mathrm{MTiO}_{3}\right.$ with $\mathrm{M}=\mathrm{Ba}, \mathrm{Sr}, \mathrm{Ca}$, or $\mathrm{Mg}$ ). For these compounds the conduction band bottom is composed of empty $3 \mathrm{~d}$-orbitals of $\mathrm{V}^{5+}$ and $\mathrm{Ti}^{4+}$. 2) The $\mathrm{MMoO}_{4}$ and $\mathrm{RENbO}_{4}$ compounds together with $\mathrm{LiNbO}_{3}$ and $\mathrm{CaNb}_{2} \mathrm{O}_{6}$. Here the bottom of the conduction band is composed of the empty 4d-orbitals. 3) The $\mathrm{MWO}_{4}$ and $\mathrm{RETaO}_{4}$ compounds with $5 \mathrm{~d}$-orbital conduction band bottoms. $\mathrm{PbWO}_{4}$ with 6 p-orbitals at the conduction band bottom is also included. The above compounds show relatively strong electron binding energy $(\approx-4 \mathrm{eV}$ to $\approx-3 \mathrm{eV})$ at the conduction band bottom, or equivalently they show large electron affinity. It turns out that the lanthanide impurity $5 \mathrm{~d}$-level is always located above $E_{C}$ and consequently $5 \mathrm{~d}-4 \mathrm{f}$ emission is never observed. Such a situation favors the observation of intervalence charge (=electron) transfer (IVCT) from for example the $\mathrm{Pr}^{3+}$ or the $\mathrm{Tb}^{3+}$ $4 \mathrm{f}^{n}$ ground state directly to the transition metal cation. These transitions are indicated by arrows 1) and 2) in Fig. 1. Low lying conduction band states also affect the quenching of the emission from the ${ }^{3} P_{0}$ level of $\mathrm{Pr}^{3+}$ or the ${ }^{5} D_{3}$ and ${ }^{5} D_{4}$ levels of $\mathrm{Tb}^{3+}$. We will utilize the IVCT band energies and the quenching data to construct the HRBE and VRBE schemes. By comparing the VRBE data of

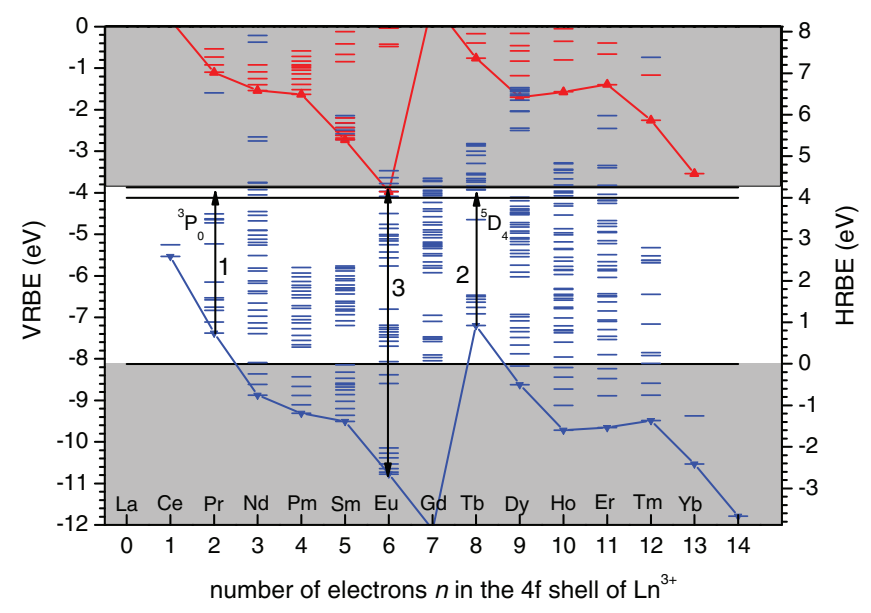

Figure 1. The host referred binding energy (right hand scale) and vacuum referred binding energy (left hand scale) of electrons in lanthanide impurity and host band states in $\mathrm{GdVO}_{4}$. Arrow 1) is the $\mathrm{Pr}^{3+}$ IVCT transition, arrow $2)$ is the $\mathrm{Tb}^{3+}$ IVCT transition, and arrow 3$)$ denotes $U(6, G d V O 4)$. 
the different compounds clear trends are observed with changing size of the rare earth or alkaline earth that will be interpreted with the crystal field splitting of $n$ d-states and the chemical shift model. Also a clear trend is revealed with the type of $n$ d-orbital. Binding is strongest for the compact 3d-orbitals and weakest for the extended 5 d-orbitals.

\section{Methodology}

With the chemical shift model only a few parameters are required to construct a VRBE scheme for the lanthanides in a compound. The most crucial parameter is the $4 \mathrm{f}$-electron Coulomb repulsion energy $U(n, A)$ which is defined as the Coulomb repulsion experienced by an electron when it is added to the $4 \mathrm{f}$-orbital of a trivalent lanthanide ion in compound $A$ that already contains $n$ electrons. $U(6, A)$ is then the energy difference between the $4 \mathrm{f}^{6}$ ground state of $\mathrm{Eu}^{3+}$ with the $4 \mathrm{f}^{7}$ ground state of $\mathrm{Eu}^{2+}$ as indicated by arrow 3 ) in Fig. 1. Knowledge on $U(6, A)$ alone already defines the location of all the $4 \mathrm{f}^{n}$ ground and excited state levels of each divalent and trivalent lanthanide impurity relative to the vacuum level. ${ }^{4,6,7}$ It turns out to be difficult to derive accurate values for $U(6, A)$ from spectroscopy. Since $U(6, A)$ is strongly related to the nephelauxetic effect and since that effect is connected with the electronegativity $\chi$ of the cations that bind the anion ligands, ${ }^{7,8}$ we took a different approach. We deal in this work with $\mathrm{Ba}(\chi=0.89), \mathrm{Sr}(\chi=0.95), \mathrm{Ca}(\chi=1.00), \mathrm{Mg}(\chi=1.31)$ and the rare earths $\mathrm{La}(\chi=1.10), \mathrm{Gd}(\chi=1.20), \mathrm{Y}(\chi=1.22), \mathrm{Lu}(\chi=1.27)$, and $\operatorname{Sc}(\chi=1.36)$ which all have relatively small electronegativity $\chi$. Table I shows the corrected Pauling electronegativity of the TM cations, which range from 1.50 to $2.36 .^{9}$ Table I also shows the free atom $\mathrm{Q}^{t h}$ ionization potentials ${ }^{10}$ that correlate strongly with the electronegativity.

Electronegativity is not a unique atomic concept since it depends on the valence of the cation and on the nature of the coordinating anion. Therefore, the electronegativity of the cations in a compound can only provide an indication of the value for $U(6, A)$. Table II compiles the TM compounds studied in this work together with the valence weighted average cation electronegativity $\chi_{a v}$ in column 2 . For $\mathrm{CaTiO}_{3}, \mathrm{SrTiO}_{3}$, and $\mathrm{BaTiO}_{3}$ VRBE schemes were already presented in Ref. 7 and a motivation for the chosen value of $U(6, A)=6.7 \mathrm{eV}$ was provided there. Since the rare earth tantalates have $\chi_{a v}$ similar to those titanates, likewise a value of $U(6, A)=6.70 \mathrm{eV}$ will be adopted. For $\mathrm{MgTiO}_{3}$ and $\mathrm{ScTaO}_{4}$ a slightly larger value of $6.75 \mathrm{eV}$ is used to take into account the higher $\chi_{a v}$ due to the contribution from the small cations $\mathrm{Mg}^{2+}$ and $\mathrm{Sc}^{3+} \cdot \chi_{a v}$ for the vanadates and niobates are between 1.4 to 1.5 in Table II, and are larger than those for the titanates and tantalates. They compare well with the $\chi_{a v}$ for aluminate compounds like $\mathrm{YAlO}_{3}$ and $\mathrm{Y}_{3} \mathrm{Al}_{5} \mathrm{O}_{12}$ with well established $U(6, A)=6.8 \mathrm{eV}$. We will therefore use $U(6, A)=6.8 \mathrm{eV}$ for the vanadates and niobates in this work. The molybdates and tungstates have a higher value again for $\chi_{a v}$, i.e., between 1.9 and 2.0 which are typical values for rare earth phosphate compounds with $U(6, A)$ between 7.0 and $7.2 \mathrm{eV}$. In this work we will adopt a value of $U(6, A)=7.0 \mathrm{eV}$ for the molybdates and $7.1 \mathrm{eV}$ for the tungstates.

Table I. Compilation of properties of the transition metals and the values used for $U(6, A)$ in this work. The in-crystal Shannon radius $r_{S}$ for 6 fold coordinated $T M^{Q+}$ is in pm units. The corrected Pauling electronegativity $\chi$ is dimensionless. The free ion $Q^{t h}$ ionization potential $I$ and $U(6, A)$ are in $\mathrm{eV}$.

\begin{tabular}{lllllc}
$T M^{Q+}$ & $n l$ & $r_{S}$ & \multicolumn{1}{c}{$\chi$} & $I^{Q^{t h}}$ & $U(6, A)$ \\
\hline $\mathrm{V}^{5+}$ & $3 \mathrm{~d}$ & 68 & $1.63(2+)$ & 65.3 & 6.80 \\
$\mathrm{Ti}^{4+}$ & $3 \mathrm{~d}$ & 75 & $1.54(2+)$ & 43.3 & 6.70 \\
$\mathrm{Mo}^{6+}$ & $4 \mathrm{~d}$ & 73 & $2.16(2+)$ & 68.8 & 7.00 \\
$\mathrm{Nb}^{5+}$ & $4 \mathrm{~d}$ & 78 & 1.60 & 50.6 & 6.80 \\
$\mathrm{~W}^{6+}$ & $5 \mathrm{~d}$ & 74 & $2.36(2+)$ & 64.8 & 7.10 \\
$\mathrm{Ta}^{5+}$ & $5 \mathrm{~d}$ & 78 & 1.50 & 48.3 & 6.70
\end{tabular}

With the above values for $U(6, A)$ the VRBE of an electron in all lanthanide states are known, and one only needs to place the host valence and conduction bands relative to those lanthanide states. The most convenient method is to use the $\mathrm{Eu}^{3+}$ charge transfer band energy $E^{C T}(6,3+, A)$ to pin $E_{V}$ with respect to the divalent lanthanide levels. However for the TM-compounds $E^{C T}(A)$ usually appears too close or even above the host absorption band as in Fig. 1 preventing such pinning. Another method is to pin $E_{C}$ by using data on $\mathrm{Pr}^{3+}$ and $\mathrm{Tb}^{3+}$ IVCT energies. ${ }^{11,12}$ After IVCT the electron transferred from $\mathrm{Pr}^{3+}$ or $\mathrm{Tb}^{3+}$ to the TM is still bonded to either $\mathrm{Pr}^{4+}$ or $\mathrm{Tb}^{4+}$ left behind. The VRBE of the transferred electron, indicated by the endpoints of arrows 1) and 2) in Fig. 1, is assumed to be located between $E_{C}$ and $E_{X} . E_{X}$ is then the VRBE of the electron in the host exciton state with an electron-hole binding energy $E_{e-h}^{e x} \equiv E_{C}-E_{X}$. The ${ }^{3} P_{0}$ level of $\mathrm{Pr}^{3+}$ and the ${ }^{5} D_{4}$ level of $\mathrm{Tb}^{3+}$ are relatively close to the conduction band in Fig. 1. The emission due to transitions from those levels are then quenched at fairly low temperature, and data on such quenching will be used to estimate the energy difference between the ${ }^{3} P_{0}$ and ${ }^{5} D_{4}$ levels and $E_{X}$ or $E_{C}$.

\section{Results and Discussion}

HRBE schemes for the lanthanides in various transition metal compounds based on IVCT data were reported already for several of the compounds in this work. ${ }^{11-14,17}$ First VRBE schemes on titanates appeared in Ref. 7. For those and all the other compounds in Table II an extensive literature search was done to derive more and more reliable information on the host exciton creation energy $E^{e x}(A)$. In this work we always use or estimate the value for $E^{e x}$ that pertains to $\approx 10 \mathrm{~K}$. The binding energy of the electron and hole in the exciton is usually not known. For wide band gap oxide and fluoride compounds the binding energy is often estimated at about $8 \%$ of $E^{e x} \cdot{ }^{15}$ However in small band gap compounds with a high dielectric constant the binding energy is of a smaller percentage. ${ }^{16}$ In this work we will adopt, like for the titanates in Ref. 7, an estimated value of $250 \mathrm{meV}$ for all compounds. For each compound spectroscopic data was also collected on $\mathrm{Pr}^{3+}, \mathrm{Tb}^{3+}$ and $\mathrm{Eu}^{3+}$ dopants and occasionally $\mathrm{Ce}^{3+}$. $\mathrm{Ce}^{3+}, \mathrm{Pr}^{3+}, \mathrm{Tb}^{3+}$ appear to have the $4 \mathrm{f}^{n}$ ground state level inside the forbidden band, and then one may observe the IVCT bands or employ the luminescence quenching properties of the characteristic $\mathrm{Pr}^{3+}$ and $\mathrm{Tb}^{3+}$ emission lines. Whenever the ground state of $\mathrm{Eu}^{2+}$ is well below $E_{C}$ one may also observe the CT-band.

In Appendix A a detailed account with all references is provided on the obtained data used to construct the VRBE schemes. The final results are compiled in Table II and displayed in the stacked band diagram of Fig. 2. The figure shows for each compound in Table II the $\mathrm{Tb}^{3+}$ ground state and ${ }^{5} D_{3}$ and ${ }^{5} D_{4}$ excited state electron binding energies, the ${ }^{3} P_{0}$ excited state of $\mathrm{Pr}^{3+}$, and the $\mathrm{Eu}^{2+}$ ground state energy. One might equally well construct a scheme with any other level from any other lanthanide but the ones chosen are the most relevant for this work. The energy of charge transfer $E^{C T}$ for $\mathrm{Eu}^{3+}$ compiled in column 4 of Table II is for most compounds obtained from $\mathrm{Eu}^{3+}$ excitation spectra, but in compounds where the $\mathrm{Eu}^{2+}$ ground state appeared too close to $E_{X}$ it has been inferred from IVCT and luminescence quenching data involving $\operatorname{Pr}^{3+}$ and $\mathrm{Tb}^{3+} . E^{C T}$ is then listed within brackets. With $E^{C T}$ and $U(6, A)$ the values for $E_{V}$ are obtained with the chemical shift model, and adding $E^{e x}$ (column 3 ) then provides $E_{X}$ (column 6) which is shown as a solid data symbol in Fig. 2. $E_{C}$ is then at $250 \mathrm{meV}$ higher energy. The energy difference $\triangle E_{X-5} D_{4}$ between the $\mathrm{Tb}^{3+}{ }^{5} D_{4}$ level and $E_{X}$ is compiled in column 10. Table II also compiles information (when available) on the IVCT band energy $E^{I V C T}$ for $\mathrm{Tb}^{3+}$ and for $\operatorname{Pr}^{3+}$

Table II and Fig. 2 reveal various trends. When the size of the rare earth or alkaline earth cation decreases $E_{X}$ and $E_{C}$ tend to decrease also. $E_{X}=-3.0 \mathrm{eV}$ for $\mathrm{BaWO}_{4}$ and it decreases to $-3.2 \mathrm{eV}$ for $\mathrm{SrWO}_{4}$ and $-3.6 \mathrm{eV}$ for $\mathrm{CaWO}_{4}$. Similar trends are observed for the vanadates, titanates, molybdates, and the tantalates. The trend is not seen for the niobates. The bottom of the conduction band is dominated by the $n d$ orbitals of the TM cation, and therefore with the 


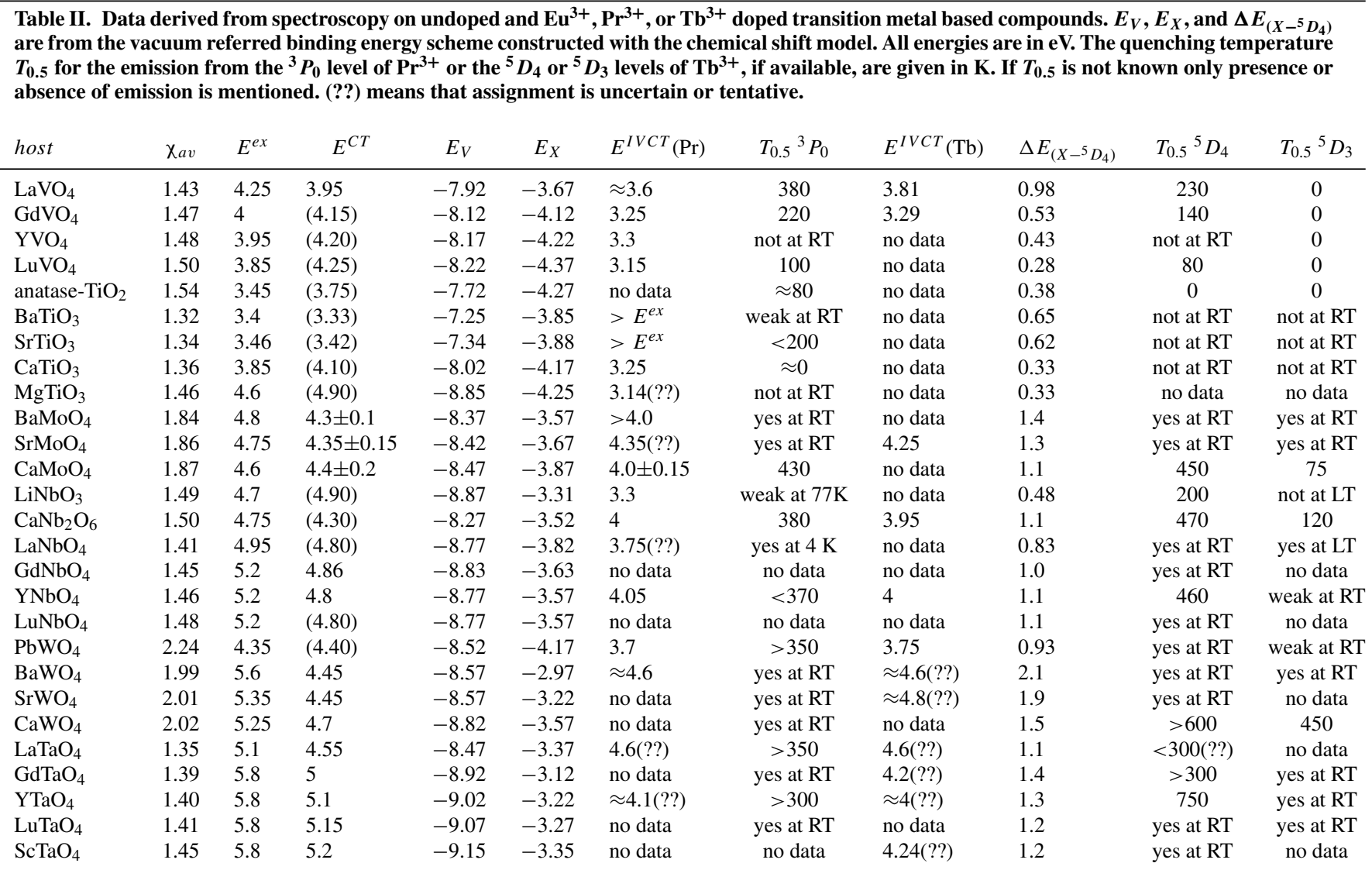

binding energy of an electron in the $n d^{1}$ state. Much information is already available on the VRBE in the $5 \mathrm{~d}^{1}$ level of $\mathrm{Ce}^{3+}$ in compounds. On average it is $-1.8 \mathrm{eV}$, and compound to compound variation by $\pm 1 \mathrm{eV}$ is almost entirely caused by variation in the crystal field splitting of the 5d-level energies. ${ }^{18}$ The same was found for the VRBE of the $3 \mathrm{~d}^{1}$ electron of $\mathrm{Ti}^{3+}$ as impurity in wide band gap compounds and semiconductors. It is on average at $-4 \mathrm{eV}$ and also with a compound to compound variation of $\pm 1 \mathrm{eV}$. Again variations in crystal field splitting were held responsible. ${ }^{18}$
The TM cations in the compounds of this work are either 4-fold coordinated in a (distorted) tetrahedron or 6-fold in a (distorted) octahedron. Then, when the size of the rare earth or alkaline earth cation increases not only the lattice parameter increases but usually also the bondlength in the TM-tetrahedron or TM-octahedron. As a result the crystal field splitting will decrease. It translates to less negative $E_{C}$. $\mathrm{PbWO}_{4}$ has $E_{X}$ at $-4.17 \mathrm{eV}$ which is lower than for the alkaline earth tungstates. Here the bottom of the conduction band is formed by $6 \mathrm{p}$ $\mathrm{Pb}$-orbitals and not by the $5 \mathrm{~d} \mathrm{~W}$-orbitals.

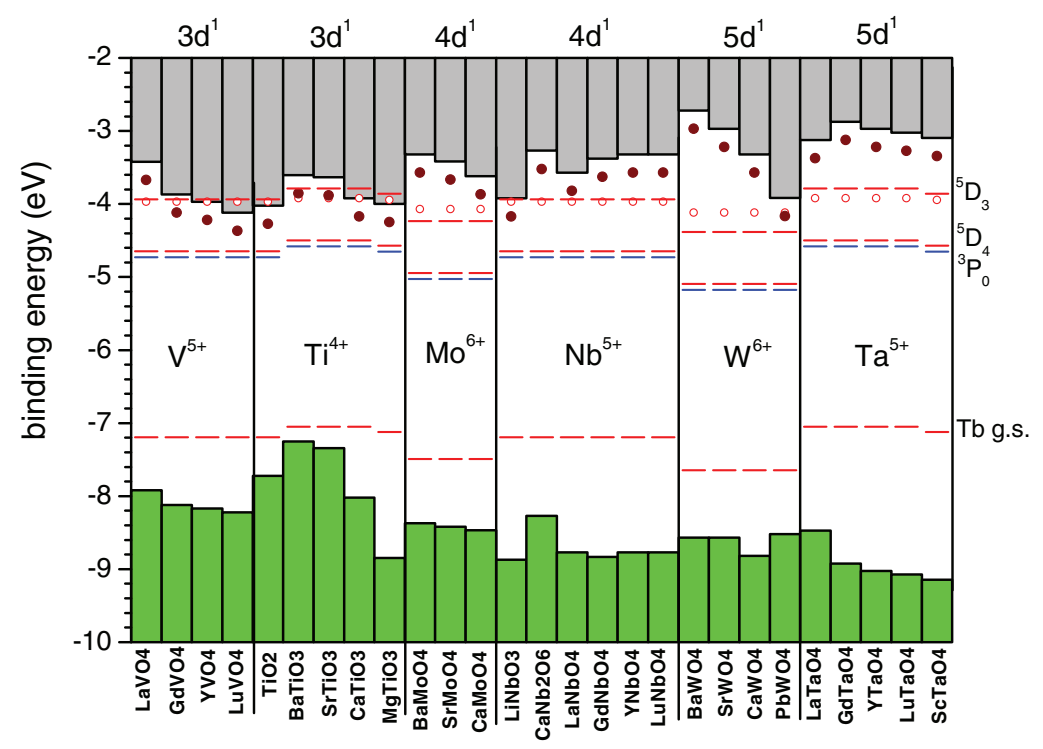

Figure 2. Stacked band diagram of TM-compounds showing the energy of the $\mathrm{Pr}^{3+}{ }^{3} P_{0}$ level, the $\mathrm{Tb}^{3+}$ ground state, ${ }^{5} D_{4}$, and ${ }^{5} D_{3}$ levels. The solid symbol donotes $E_{X}(A)$ and the open symbol $E_{4 f}(7,2+, A)$ 


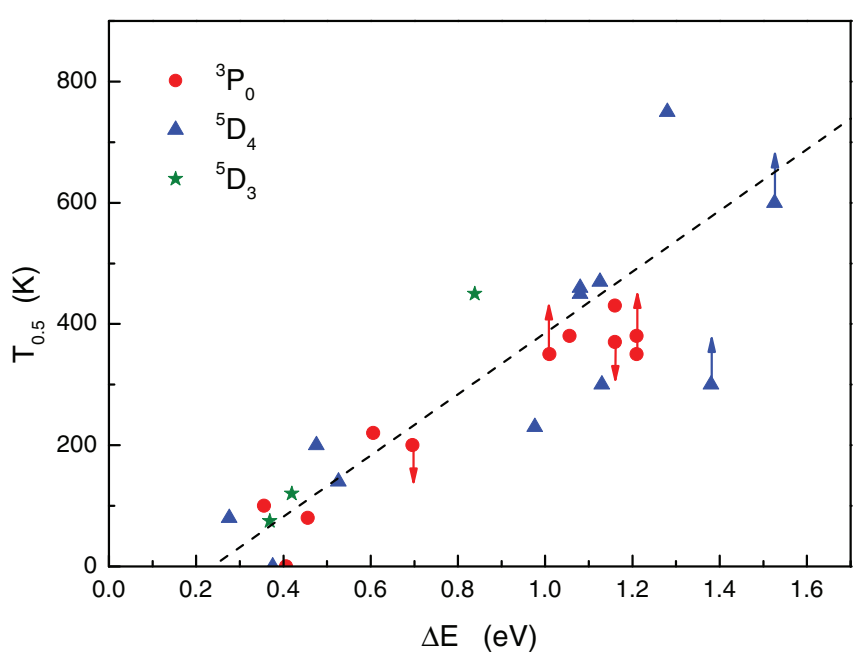

Figure 3. Stacked band diagram of TM-compounds showing the energy of the $\operatorname{Pr}^{3+}{ }^{3} P_{0}$ level, the $\mathrm{Tb}^{3+}$ ground state, ${ }^{5} D_{4}$, and ${ }^{5} D_{3}$ levels. The solid symbol donotes $E_{X}(A)$ and the open symbol $E_{4 f}(7,2+, A)$.

Column 10 in Table II shows that $\Delta E_{\left(X-{ }^{5} D_{4}\right)}$ is largest for the tungstates where emission from the ${ }^{5} D_{4}$ level appears very temperature stable. It is small for the titanates where $\mathrm{Tb}^{3+}$ emission is not observed at all at room temperature. The smallest value is for $\mathrm{LuVO}_{4}$ where the ${ }^{5} D_{4}$ emission shows a very low quenching temperature of $T_{0.5}=80 \mathrm{~K}$. The ${ }^{3} P_{0}$ level for $\operatorname{Pr}^{3+}$ is within our models always at $0.080 \mathrm{eV}$ lower energy than the ${ }^{5} D_{4}$ level of $\mathrm{Tb}^{3+}$, and then the quenching temperature for the ${ }^{3} P_{0}$ emission should strongly correlate with that from the ${ }^{5} D_{4}$ level. This can indeed be seen in Table II. It is also demonstrated in Fig. 3 where the quenching temperature $T_{0.5}$ for the ${ }^{3} P_{0}$ and ${ }^{5} D_{4}$ emission is shown against the energy difference $\Delta E$ between the emitting level and $E_{X}$. Quenching temperature for both emissions increase with $\Delta E$ at about a similar pace. The ${ }^{5} D_{3}$ level is always $0.711 \mathrm{eV}$ above the ${ }^{5} D_{4}$ level, and the data for $\mathrm{CaWO}_{4}$, $\mathrm{CaNb}_{2} \mathrm{O}_{6}$, and $\mathrm{CaMoO}_{4}$ fits within the picture.

Assuming that thermal quenching proceeds by thermal activation of the electron in the emitting state to the IVCT state, $T_{0.5}$ is reached when the radiative decay rate $\Gamma_{\nu}$ equals the thermal quenching rate

$$
\Gamma_{\nu}=\Gamma_{0} e^{-\frac{\Delta E}{k_{B} T_{0.5}}}
$$

where $k_{B}$ is the Boltzmann constant and $\Gamma_{0}$ is the attempt rate which is about equal to the frequency of the main vibrational mode at the luminescence center site. With $\Delta \mathrm{E}$ in $\mathrm{eV}$ one may write

$$
T_{0.5}=\frac{11590}{\ln \left(\frac{\Gamma_{0}}{\Gamma_{\nu}}\right)} \Delta E .
$$

With typical phonon frequencies of $500-1000 \mathrm{~cm}^{-1}, \Gamma_{0} \approx 2 \times$ $10^{13} \mathrm{~Hz}$, and with typical $\mathrm{Tb}^{3+}{ }^{5} D_{4}$ radiative decay rate $\Gamma_{v} \approx 10^{3}$ $\mathrm{Hz}$ one obtains $T_{0.5} \approx 500 \Delta E$. The ${ }^{3} P_{0}$ level of $\operatorname{Pr}^{3+}$ has larger decay rate of typically $1-2 \times 10^{4} \mathrm{~Hz}$ which leads to $T_{0.5} \approx 550$ $\Delta E$. It is not too much different from that for the ${ }^{5} D_{4}$ emission. The dashed line in Fig. 3 was drawn with a slope of $500 \mathrm{~K} / \mathrm{eV}$, and indeed the data scatter around such a predicted slope. Actually one may not expect better agreement for various reasons; 1) $\Gamma_{0}$ and $\Gamma_{\nu}$ for different compounds are not the same, 2) the VRBE schemes have typical errors of few $0.1 \mathrm{eV}$ which are then also present in $\Delta E, 3$ ) the $T_{0.5}$ may be reduced by additional quenching processes like multiphonon relaxation or quenching by unknown defects. Nevertheless, the general trend follows the simple predictive equation, and this is regarded as supporting evidence that the VRBE schemes and the entire method of its construction are valid. Note that the dashed line has an intercept at $\Delta E \approx 0.25 \mathrm{eV}$. It suggests that the crossing point between the parabola representing the ${ }^{5} D_{4},{ }^{5} D_{3}$, or ${ }^{3} P_{0}$ level and the parabola

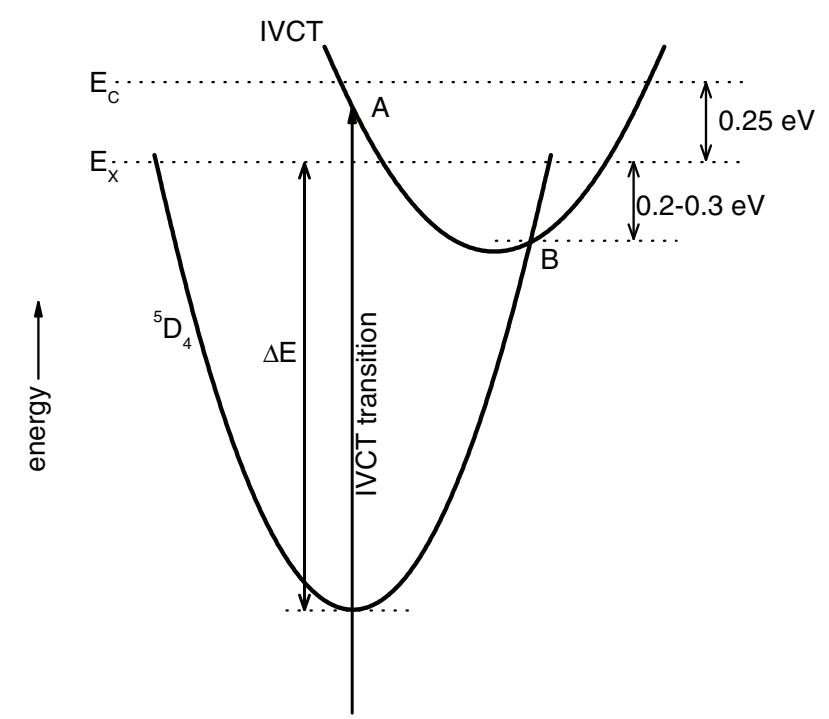

Figure 4. Illustration of thermal quenching of $\mathrm{Tb}^{3+}{ }^{5} D_{4}$ luminescence within a configurational coordinate diagram. The IVCT transition brings the electron to point $\mathrm{A}$ in between $E_{C}$ and $E_{X}$. Thermal quenching proceeds via point $\mathrm{B}$ located 0.2-0.3 eV below $E_{X}$.

representing the IVCT state in a configuration coordinate diagram is about $0.2-0.3 \mathrm{eV}$ below $E_{X}$. The situation is illustrated in Fig. 4.

Knowing that the absence or presence of ${ }^{5} D_{4},{ }^{5} D_{3}$, or ${ }^{3} P_{0}$ emission and the quenching temperatures are connected with the energy difference between the emitting states and conduction band related states one may understand the luminescence properties of lanthanides in solid solutions. In the solid solution of $\mathrm{Ca}_{1-x} \mathrm{Sr}_{x} \mathrm{TiO}_{3}$ the VRBE in the exciton state $E_{X}$ and at the bottom of the conduction band $E_{C}$ will move upward when the $\mathrm{Sr}$ fraction increases. The VRBE of the lanthanide levels are not expected to change significantly. One may then engineer the energy difference between emitting levels of $\mathrm{Pr}^{3+}$ and $E_{C}$ by adjusting the $\mathrm{Sr}$ fraction. This will affect the ratio between blue ${ }^{3} P_{0}$ and red ${ }^{1} D_{2} \operatorname{Pr}^{3+}$ emission as was indeed observed in Refs. 19-21. Possibly something similar happens when $\mathrm{Al}^{3+}$ is added to $\mathrm{Pr}^{3+}$ or $\mathrm{Tb}^{3+}$ doped $\mathrm{SrTiO}_{3}$. The otherwise absent emission from $\mathrm{Tb}^{3+}$ starts to appear ${ }^{22}$ and that from $\mathrm{Pr}^{3+}$ is significantly enhanced with increasing $\mathrm{Al}$ content. ${ }^{23}$

The conduction band bottom of $\mathrm{REVO}_{4}, \mathrm{RENbO}_{4}$, or $\mathrm{RETaO}_{4}$ is composed of the empty $3 \mathrm{~d}, 4 \mathrm{~d}$, or $5 \mathrm{~d}$ orbitals of $\mathrm{V}^{5}+, \mathrm{Nb}^{5+}$, or $\mathrm{Ta}^{5+}$. An electron inside the conduction band then occupies an orbital strongly related to the lowest crystal field split $3 \mathrm{~d}, 4 \mathrm{~d}$, or $5 \mathrm{~d}$ level of $\mathrm{V}^{4+}, \mathrm{Nb}^{4+}$, or $\mathrm{Ta}^{4+}$. The VRBE of such electron clearly moves upwards (becomes less negative) in going from $3 \mathrm{~d}$ to $4 \mathrm{~d}$ to $5 \mathrm{~d}$ orbitals. For example, $E_{X}=-4.12 \mathrm{eV}$ for $\mathrm{GdVO}_{4},-3.64 \mathrm{eV}$ for $\mathrm{GdNbO}_{4}$, and -3.12 for $\mathrm{GdTaO}_{4}$. The same applies when the $4 \mathrm{~d}$-orbital conduction band VRBE of $6+\mathrm{TM}$ cations in $\mathrm{MMoO}_{4}$ are compared with the $5 \mathrm{~d}$ energies in $\mathrm{MWO}_{4}$, For example $E_{X}=-3.87 \mathrm{eV}$ in $\mathrm{CaMoO}_{4}$ and -3.55 in $\mathrm{CaWO}_{4}$. This trend for the 5+ and 6+ TM cations was also observed for $4+$ cations. Fig. 5 is reproduced from data in Ref. 24 for compounds where the conduction band bottom is composed of the unoccupied $n d$-orbitals of the $4+$ cations $\mathrm{Ti}^{4+}(n=3), \mathrm{Zr}^{4+}(n=4)$, $\mathrm{Ce}^{4+}(n=5)$, or $\mathrm{Th}^{4+}(n=6)$. When comparing similar types of compounds with $n$ d cations of the same charge, $E_{X}$ and $E_{C}$ consistently move up as the principle quantum number $n$ increases. In an accompanying paper we will conclude precisely the same for the TM elements as dopants in wide band gap and semiconducting compounds. ${ }^{25}$ In that work it will be shown that the trend can be related to the ionization potentials of the free TM atoms.

Finally we will address the clear trends in the binding energy $E_{V}$ at the top of the valence band in Fig. 2. Generally $E_{V}$ becomes lower with smaller sized RE or M. The effect is not large, and although the values for $E^{C T}$ that determine $E_{V}$ were in some cases somewhat tentatively 


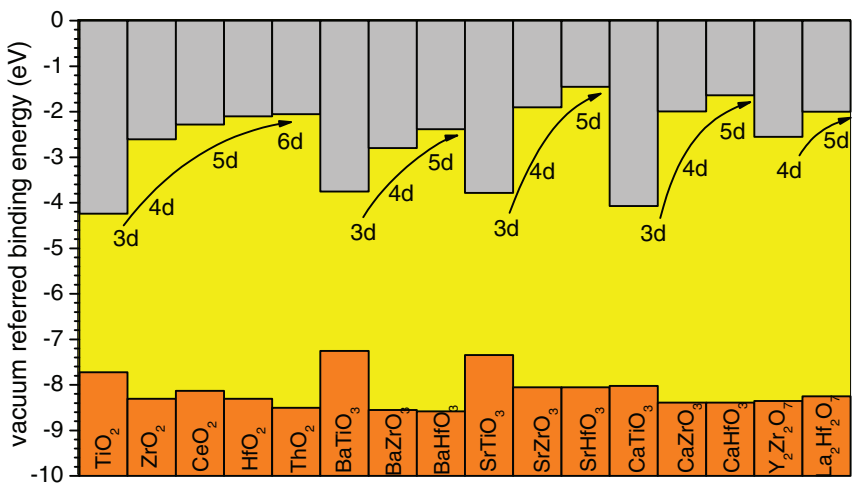

Figure 5. Stacked band diagram of $\mathrm{Ti}^{4+}, \mathrm{Zr}^{4+}, \mathrm{Ce}^{4+}, \mathrm{Hf}^{4+}$, and $\mathrm{Th}^{4+}$ based compounds constructed from data in.7 The end points of the up and down pointing vertical bars indicate $E_{V}$ and $E_{C}$.

assigned the effect appears consistent. Similar observations were made for non-TM based compounds like the series $\mathrm{Ba}-, \mathrm{Sr}-, \mathrm{CaF}_{2},{ }^{6} \mathrm{La}-, \mathrm{Gd}-$, $\mathrm{Y}-, \mathrm{LuAlO}_{3},{ }^{6}$ and La-, Gd-, Y-, $\mathrm{LuPO}_{4} .{ }^{5}$ It is explained by the chemical shift of the anion electron binding energy. This shift is negative due to the attractive potential of the surrounding cations, and the magnitude increases with shorter anion to cation bondlength.

\section{Conclusions}

The VRBE schemes for the lanthanides in rare earth and alkaline earth transition metal compounds have been constructed using the methods of the chemical shift model. The chosen values for the Coulomb repulsion energy $U(6, A)$ were motivated by the average electronegativity of the cations as listed in Table II. In the selected compounds of this work the bottom of the conduction band $E_{C}$ falls between about $-3 \mathrm{eV}$ and $-4 \mathrm{eV}$. Such a low lying conduction band has consequences for lanthanide luminescence and spectroscopy. The $\mathrm{Eu}^{2+}$ ground state, which is always near $-4 \mathrm{eV} \pm 0.3 \mathrm{eV}$, is close to $E_{X}$. Under such circumstances a $\mathrm{Eu}^{3+} \mathrm{CT}$-band cannot be discriminated well from the host excitation bands and VRBE scheme construction cannot be based on CT-band energy data. Another consequence is that the lowest $5 \mathrm{~d}$ states of the lanthanides are always inside the conduction band. This prevents $5 \mathrm{~d}-4 \mathrm{f}$ emission, but it enables us to observe the weak IVCT bands of $\mathrm{Pr}^{3+}$ and $\mathrm{Tb}^{3+}$ which then forms a basis for VRBE scheme construction. The obtained VRBE schemes as shown in Fig. 2 demonstrate various trends. The binding energy at the conduction band bottom is mainly given by the binding energy of the $n$ d state of the TM cation which is subject to crystal field splitting. A larger sized rare earth or alkaline earth cation tends to reduce that splitting and $E_{C}$ moves upwards. Also a clear correlation is found with the type of TM. Generally with higher principle quantum number $n$ of the $n$ d conduction band orbital $E_{C}$ tends to rise. $E_{C}$ also tends to rise with smaller positive charge state of the TM cation. This implies that $E_{C}$ is lowest for the $\mathrm{V}^{5+} 3 \mathrm{~d}$ compounds and highest for the $\mathrm{Ta}^{5+} 5 \mathrm{~d}$ compounds. The obtained VRBE schemes are fully consistent with the absence or presence of and the observed quenching temperature for the $\operatorname{Pr}^{3+}{ }^{3} P_{0}$ emission and $\mathrm{Tb}^{3+}{ }^{5} D_{4}$ and ${ }^{5} D_{3}$ emission.

\section{Appendix A}

Below an account is given on how the data in Table II and used for Fig. 2 were obtained with all the references to the consulted literature. We will start with data to derive $E^{e x}(L T)$ followed by data on $\mathrm{Eu}^{3+}$ to determine $E^{C T}$. Next data on $\mathrm{Pr}^{3+}$ and $\mathrm{Tb}^{3+}$ to determine IVCT energies and luminescence quenching temperatures are presented. An unambiguous discrimination between host bands, IVCT bands and CT-bands can be difficult or even impossible. Near a defect, the energy for host excitation can be several $0.1 \mathrm{eV}$ different from that of the pure host material which complicates determination of $E^{e x}$. Whenever $E^{e x}$ in a transition metal compound is near $5.0 \mathrm{eV}$, the host excitation is likely to overlap with the $\mathrm{Eu}^{3+}$ charge transfer band. Also when the $\mathrm{Pr}^{3+}$ and $\mathrm{Tb}^{3+}$ ground state levels are less than $1 \mathrm{eV}$ above the top of the valence band, the corresponding IVCT bands tend to merge with the host excitation bands. These all lead to difficulties in discrimination between and proper assignment of bands. All assignments made or suggested in this work were done in such a manner that they are most consistent with all available data and whit each other.

\section{The vanadates}

LaVO $_{4}$. The host luminescence excitation spectrum reveals a band at $307 \mathrm{~nm}$ $(4.04 \mathrm{eV})$ that shifts to $291 \mathrm{~nm}(4.26 \mathrm{eV})$ when temperature is decreased from $360 \mathrm{~K}$ to $8 \mathrm{~K} .{ }^{13}$ In addition there is a band at a shorter wavelength of $271 \mathrm{~nm}(4.58 \mathrm{eV})$. The two excitation bands are connected with two different broad band host related emissions. The one connected with the $4.26 \mathrm{eV}$ excitation maximum is fully quenched at room temperature. ${ }^{13}$ Similar excitation band energies were observed with $\mathrm{Dy}^{3+}$ and with $\mathrm{Eu}^{3+}$ doping. ${ }^{26,27} \mathrm{~Tb}^{3+},{ }^{28} \mathrm{Eu}^{3+},{ }^{27} \mathrm{Dy}^{3+26}$ doped $\mathrm{LaVO}_{4}$ reveal only the host excitation band near $272 \mathrm{~nm}(4.55 \mathrm{eV})$. Apparently at room temperature efficient energy transfer to lanthanide dopants takes place only from the higher energy host band. We will adopt the low energy band to represent $E^{e x}(\mathrm{LT})=4.25 \mathrm{eV}$ in this work. There are indications for $\mathrm{a} \mathrm{Eu}^{3+} \mathrm{CT}$-band as a faint shoulder at $315 \mathrm{~nm}(3.95 \mathrm{eV})$ on the long wavelength side of the host excitation band in Refs. 13 and 14 and as a clear shoulder band in Ref. 27 and 29. The energy for the $\operatorname{Pr}^{3+}$ IVCT band of $\approx 3.6 \mathrm{eV}$ is estimated from Boutinaud et al. ${ }^{30}$ The emission from the ${ }^{3} P_{0}$ level shows $T_{0.5}=380 \mathrm{~K} .{ }^{40}$ Under excitation in the host band there is no emission from the ${ }^{5} D_{3}$ level for all vanadate compounds, and that from the ${ }^{5} D_{4}$ level in $\mathrm{LaVO}_{4}$ has estimated $T_{0.5}=230 \mathrm{~K} .{ }^{13}$

$\mathbf{G d V O}_{4}$. Many reports on the spectroscopy of lanthanides in $\mathrm{GdVO}_{4}$ can be found in literature. Irrespective of the type of dopant they always reveal the first host excitation maximum near $323 \mathrm{~nm}(3.85 \mathrm{eV})^{31}$ at room temperature. ${ }^{32}$ report that the luminescence efficiency of $\mathrm{Eu}^{3+}$ emission depends on the amount of crystallinity and the best samples show excitation maximum near $312 \mathrm{~nm}(3.97 \mathrm{eV})$ at room temperature. The same band at the same wavelength is observed at $15 \mathrm{~K}$ in Ref. 14 with $\mathrm{Ce}^{3+}, \mathrm{Pr}^{3+}, \mathrm{Eu}^{3+}$, or $\mathrm{Tb}^{3+}$ doping, and more reports can be found. ${ }^{33}$ We will adopt here $E^{e x}(L T)=4.0 \mathrm{eV}$ for $\mathrm{GdVO}_{4}$. Considering that a separate $\mathrm{Eu}^{3+} \mathrm{CT}$ band is not observed we conclude that $E^{C T}>E^{e x}$. The IVCT band of $\mathrm{Pr}^{3+}$ is reported as a clear shoulder band near $365 \mathrm{~nm}$ $(3.40 \mathrm{eV})$ in Ref. 30, and it is even more clearly revealed in the studies by ${ }^{14}$ at $382 \mathrm{~nm}$ $(3.25 \mathrm{eV})$ which we will adopt as the IVCT energy here. Upon excitation at $480 \mathrm{~nm}$ in the ${ }^{3} \mathrm{P}$ levels of $\mathrm{Pr}^{3+}$ emission from ${ }^{3} P_{0}$ is observed at $15 \mathrm{~K}$ that quenches with $T_{0.5}=220 \mathrm{~K}$, and the red emission from the ${ }^{1} D_{2}$ level starts to dominate the spectrum fully. $\mathrm{Tb}^{3+}$ in $\mathrm{GdVO}_{4}$ was studied in detail by ${ }^{14}$ A very clear band at $378 \mathrm{~nm}(3.29 \mathrm{eV})$ is observed and attributed to the $\mathrm{Tb}^{3+}$ IVCT band. Upon excitation exclusively emission from the ${ }^{5} D_{4}$ state is observed with $T_{0.5}=140 \mathrm{~K}$. With these values for the IVCT band one arrives at a VRBE scheme shown in Fig. 1 that predicts the $\mathrm{Eu}^{3+}$ CT-band at $4.15 \mathrm{eV}$ which is consistent with the above conclusion that $E^{C T}>E^{e x}$

YVO $_{4}$. The RT host excitation maximum is at $318 \mathrm{~nm}(3.90 \mathrm{eV})$ in $\mathrm{Dy}^{3+}$ and $\mathrm{Pr}^{3+}$ doped samples, ${ }^{34,35}$ at $332 \mathrm{~nm}(3.75 \mathrm{eV})$ in Refs. 36 and 37 , and at $326 \mathrm{~nm}(3.80 \mathrm{eV})$ in Ref. 38. For $\mathrm{Ce}^{3+}$ and $\mathrm{Eu}^{3+}$ doped samples it is at $325 \mathrm{~nm}(3.81 \mathrm{eV}) \cdot{ }^{39} \mathrm{In}$ this work we will assume for $E^{e x}(\mathrm{LT})$ a value of $3.95 \mathrm{eV}$. Like for $\mathrm{GdVO}_{4}$, see above, a Eu ${ }^{3+} \mathrm{CT}$-band is not observed and $E^{C T}>E^{e x}$. Construction of a VRBE scheme then needs to rely on the values for the $\mathrm{Pr}^{3+}$ and $\mathrm{Tb}^{3+}$ IVCT bands. That for $\mathrm{Pr}^{3+}$ is well established. It is observed as a clear band in $\operatorname{Pr}^{3+}$ excitation spectra at $380 \mathrm{~nm}(3.26 \mathrm{eV})$ in Refs. 30, 36, and 37 and also clearly at $373 \mathrm{~nm}(3.32 \mathrm{eV})$ in. ${ }^{38}$ Here we will adopt a value of $3.30 \mathrm{eV}$ for the IVCT band of $\operatorname{Pr}^{3+}$. Emission from the ${ }^{3} P_{0}$ is not observed at RT, and the red ${ }^{1} D_{2}$ emission is quenched with $T_{0.5}$ of $345 \mathrm{~K}^{40}$ irrespective of whether excitation is in the host $(320 \mathrm{~nm})$, the IVCT band $(370 \mathrm{~nm})$ or a $4 \mathrm{f}$-state $(445 \mathrm{~nm})$. Blasse and Bril have already noticed ${ }^{41}$ that $\mathrm{YVO}_{4}: 5 \% \mathrm{~Tb}^{3+}$ does not show any emission at all at room temperature.

$\mathbf{L u V O}_{4}$. The spectroscopy of $\mathrm{LuVO}_{4}$ with $\mathrm{Ce}, \mathrm{Eu}, \mathrm{Pr}$, and Tb dopants was studied in. ${ }^{14}$ The host excitation maximum for all dopants is consistently observed at $322 \mathrm{~nm}$ $(3.85 \mathrm{eV})$ which will be adopted as $E^{e x}(L T)$, and like for $\mathrm{GdVO}_{4}$ and $\mathrm{YVO}_{4}$ a $\mathrm{Eu}^{3+}$ CT-band cannot be observed and $E^{C T}>E^{e x}$. Again the VRBE scheme must be based on Pr and Tb IVCT and luminescence quenching data. ${ }^{30}$ reports a clearly resolved IVCT band at $395 \mathrm{~nm}(3.15 \mathrm{eV})$ which can be identified also in the spectra by. ${ }^{14}$ Upon excitation to the ${ }^{3} P$ levels of $\mathrm{Pr}^{3+}$ the $T_{0.5}$ of the ${ }^{3} P_{0}$ emission intensity is about $100 \mathrm{~K}$ which is significantly lower than for $\mathrm{GdVO}_{4}$. Information on $\mathrm{Tb}^{3+}$ is entirely from. ${ }^{14} \mathrm{~A}$ resolved IVCT band is not observed but excitation at $370 \mathrm{~nm}$ in an excitation tail below $E^{e x}$ does produce only emission from the ${ }^{5} D_{4}$ level. Upon excitation at $468 \mathrm{~nm}$ the ${ }^{5} D_{4}$ emission shows a low quenching temperature of $T_{0.5}=80 \mathrm{~K}$.

\section{The titanates}

The VRBE schemes for anatase- $\mathrm{TiO}_{2}, \mathrm{BaTiO}_{3}, \mathrm{SrTiO}_{3}$, and $\mathrm{CaTiO}_{3}$ were already presented in Ref. 7 and the references for the values for $E^{e x}$ and the IVCT band energies can be found there. Some additional supporting data is provided below.

anatase- $\mathrm{TiO}_{2}$ Table II show that $\chi_{a v}$ for $\mathrm{TiO}_{2}$ is significantly larger than that for the $\mathrm{MTiO}_{3}$ compounds, and contrary to 7 we will adopt $U(6, A)=6.8 \mathrm{eV}$. The adopted value for the $\mathrm{Eu}^{3+} \mathrm{CT}$-energy is lowered by $0.05 \mathrm{eV}$ in order to arrive at the same values for $E_{V}$ and $E_{X}$ as in.7

BaTiO $_{3}$. With $1 \% \mathrm{Pr}^{3+}$ doping weak emission from the ${ }^{3} P_{0}$ level is observed at RT but that from the ${ }^{1} D_{2}$ level is 20 times stronger. ${ }^{42}$ Information to derive $T_{0.5}$ for $\operatorname{Pr}^{3+}$ or for $\mathrm{Tb}^{3+}$ emission lines was not found. 
$\mathrm{SrTiO}_{3}$. The emission from the $\mathrm{Pr}^{3+}{ }^{3} P_{0}$ dominates over that from ${ }^{1} D_{2}$ at $77 \mathrm{~K}$ upon excitation in the host band, ${ }^{20}$ and at $350 \mathrm{~K}$ the intensity has reduced by a factor of two compared to RT $\left(0.2 \% \mathrm{Pr}^{3+}\right)$. In a study by ${ }^{23}$ at $0.2 \% \mathrm{Pr}^{3+}$ doping concentration ${ }^{3} P_{0}$ dominates at $20 \mathrm{~K}$ and it is fully quenched at room temperature which suggests $T_{0.5}$ $<200 \mathrm{~K} \mathrm{SrTiO}_{3}$ does not show $\mathrm{Tb}^{3+}$ emission at room temperature. ${ }^{22}$

$\mathrm{CaTiO}_{3}$. The quenching temperature $T_{0.5}$ for the $\mathrm{Pr}^{3+}{ }^{1} D_{2}$ emission is at $340 \mathrm{~K}^{40}$ irrespective whether excitation is in the host $(320 \mathrm{~nm})$, the IVCT band $(370 \mathrm{~nm})$, or the $4 \mathrm{f}$ level at $445 \mathrm{~nm}$. Even down to $77 \mathrm{~K}$ emission from the ${ }^{3} P_{0}$ is not observed ${ }^{20}$ which means that $\mathrm{T}_{0.5}$ must be near $0 \mathrm{~K}$.

$\mathrm{MgTiO}_{3}$. In the work by de Haart et al ${ }^{43}$ the optical absorption edge and the onset wavelength for photocurrents is at $335 \mathrm{~nm}(3.7 \mathrm{eV})$ and the host absorption maximum is near $280 \mathrm{~nm}(4.4 \mathrm{eV})$. In Ref. $44 E^{f a}(R T)=4.05 \mathrm{eV}$ and absorption reaches maximum value near $4.5 \mathrm{eV}$. In this work we will assume $E^{e x}(L T)=4.6 \mathrm{eV}$. Information on the spectroscopic properties of $\mathrm{Eu}, \mathrm{Pr}$, and $\mathrm{Tb}$ in $\mathrm{MgTiO}_{3}$ are very scarce. In Ref. 45 weak and broad bands and shoulders are seen at $309 \mathrm{~nm}(4.0 \mathrm{eV})$ and $265 \mathrm{~nm}(4.58 \mathrm{eV})$ in the excitation spectrum of $\mathrm{Eu}^{3+}$ emission. The nature of the bands is not clear yet. Cathode luminescence in Ref. 46 shows at room temperature that the emission from the ${ }^{1} D_{2}$ level of $\mathrm{Pr}^{3+}$ is about 20 times stronger than from the ${ }^{3} P_{0}$ level. For $\mathrm{BaTiO}_{3}$ similar ratio was observed which suggests a similar distance between the $\operatorname{Pr}^{3+}$ levels and $E_{X}$. In Ref. 30, $\mathrm{Pr}^{3+}$ shows weak emission from ${ }^{1} D_{2}$ and no emission from ${ }^{3} P_{0}$ at room temperature and they attributes a band at $394 \mathrm{~nm}(3.14 \mathrm{eV})$ to the IVCT of $\mathrm{Pr}^{3+}$. Although that attribution needs further confirmation we tentatively assumed that it is correct and constructed a VRBE scheme accordingly.

\section{The molybdates}

$\mathrm{BaMoO}_{4}$. The RT absorbance of pure $\mathrm{BaMoO}_{4}$ reaches a maximum at $4.75 \mathrm{eV}(260$ $\mathrm{nm})$ in Ref. 47 and the same value is observed in Ref. 49. In this work we will adopt a value $E^{e x}(L T)=4.8 \mathrm{eV}$. $\mathrm{BaMoO}_{4}$ with $\mathrm{Tb}$, Dy, or $\mathrm{Sm}$ doping shows a common excitation band at $4.45 \mathrm{eV}(278 \mathrm{~nm})$ at RT in Ref. 50. The band shifts to $4.3 \mathrm{eV}$ (287 nm) upon $\mathrm{Eu}^{3+}$ doping. In Ref. 51 the $\mathrm{Eu}^{3+} \mathrm{CT}$ maximum is at $285 \mathrm{~nm}(4.35 \mathrm{eV})$, in Ref. 52 at $294 \mathrm{~nm}$ $(4.22 \mathrm{eV})$, in Ref. 53 at $270 \mathrm{~nm}(4.59 \mathrm{eV})$. It seems that $E^{C T}=4.3 \pm 0.1 \mathrm{eV}$ and then with the constructed VRBE scheme the $\mathrm{Pr}^{3+}$ and $\mathrm{Tb}^{3+}$ IVCT bands are predicted near $4.3 \mathrm{eV}$. With $\mathrm{Pr}^{3+}$ doping a shoulder absorption band develops near $310 \mathrm{~nm}(4.0 \mathrm{eV})$ in Ref. 49 which may signal the onset of the $\mathrm{Pr}^{3+}$ IVCT band. At room temperature intense emission from the ${ }^{3} P_{0}$ level at $643 \mathrm{~nm}$ is observed ${ }^{49,54}$ With $5 \% \mathrm{~Tb}^{3+}$ doping at RT emission from the ${ }^{5} D_{4}$ level and even from the ${ }^{5} D_{3}$ level is observed. ${ }^{50,53}$ Observation of the emission from the ${ }^{5} D_{3}$ level at room temperature suggests larger separation between that levels and $E_{X}$ than in the above vanadates and titanates where emission from the ${ }^{5} D_{3}$ is always absent. A clear Tb ${ }^{3+}$ IVCT band is not observed in Ref. 53; it is probably too weak or obscured by the onset of host excitation.

$\mathrm{SrMoO}_{4}$. Undoped $\mathrm{SrMoO}_{4}$ shows the optical absorption maximum at $4.65 \mathrm{eV}$ in Ref. 55. With $\mathrm{Dy}^{3+}$ doping the RT luminescence excitation maximum is at at $268 \mathrm{~nm}$ $(4.6 \mathrm{eV})$ in Ref. 56 . We will adopt $E^{e x}(\mathrm{LT})=4.75 \mathrm{eV}$. In Ref. 51 the $\mathrm{Eu}^{3+}$ excitation maximum is at $285 \mathrm{~nm}(4.35 \mathrm{eV})$, in Ref. 57 at $288 \mathrm{~nm}(4.30 \mathrm{eV})$, in Ref. 53 at $270 \mathrm{~nm}$ $(4.59 \mathrm{eV})$, in Ref. 58 at $284 \mathrm{~nm}(4.35 \mathrm{eV})$, and in Ref. 59 at $295 \mathrm{~nm}(4.20 \mathrm{eV})$. The CT band seems to overlap with the host excitation maximum and accurate assignment is not possible. A value of $4.35 \pm 0.15 \mathrm{eV}$ will be adopted in this work. The $\mathrm{Pr}^{3+}$ emission excitation band at $286 \mathrm{~nm}(4.35 \mathrm{eV})$ observed in Ref. 60 suggests the location of the IVCT band. The emission from the ${ }^{3} P_{0}$ level dominates at RT. Data to derive $T_{0.5}$ was not found. With $\mathrm{Tb}^{3+}$ a long wavelength shoulder band around $290 \mathrm{~nm}(4.28 \mathrm{eV})$ on the rising excitation edge of the host and possibly $\mathrm{Tb}^{3+} 4 \mathrm{f}-5 \mathrm{~d}$ excitation band may signal a presence of a Tb ${ }^{3+}$ IVCT band in Ref. $53 . \mathrm{Tb}^{3+}$ emission from the ${ }^{5} D_{4}$ level is observed at room temperature and like in $\mathrm{BaMoO}_{4}$ even emission from the ${ }^{5} D_{3}$ level is observed with $5 \% \mathrm{~Tb}^{3+}$ concentration. ${ }^{33,56}$

$\mathrm{CaMoO}_{4}$ The excitation maximum for the $77 \mathrm{~K}$ host emission is at $4.5 \mathrm{eV}$ $(275 \mathrm{~nm})$ in Ref. 62. A broad RT excitation maximum near $270 \mathrm{~nm}(4.6 \mathrm{eV})$ is observed in Ref. 63. We will adopt $E^{e x}(L T)=4.6 \mathrm{eV}$. In Ref. 61 with $24 \%$ Eu doping the excitation maximum is at $271 \mathrm{~nm}(4.58 \mathrm{eV})$ and $\mathrm{Eu}^{3+}$ doped nanocrystals in Ref. 64 show maximum excitation at $281 \mathrm{~nm}(4.41 \mathrm{eV})$. The $\mathrm{Eu}^{3+}$ CT-band apparently strongly overlaps with the host excitation maximum and accurate assignment is not possible. Here we adopt $E^{C T}=4.4 \pm 0.2 \mathrm{eV}$. With $1 \% \mathrm{Pr}^{3+}$ a broad luminescence excitation band extending from $250 \mathrm{~nm}$ to beyond $300 \mathrm{~nm}$ is observed in Ref. 65 . The host excitation band near $260 \mathrm{~nm}$ is most likely merged with the $\mathrm{Pr}^{3+}$ IVCT band on the long wavelength side near 310 $\mathrm{nm}(4.0 \mathrm{eV})$. Emission from the ${ }^{1} D_{2}$ and ${ }^{3} P_{0}$ levels of $\mathrm{Pr}^{3+}$ are both observed at $\mathrm{RT}^{65,66}$ and the ${ }^{3} P_{0}$ emission is quenched with $T_{0.5}=430 \mathrm{~K} .{ }^{66} \mathrm{For} \mathrm{Tb}^{3+}$ doping, the excitation maximum is at $289 \mathrm{~nm}(4.29 \mathrm{eV})$ in Ref. 67 and like for $\mathrm{Pr}^{3+}$ the IVCT band most likely has merged with the host band. The ${ }^{5} D_{4}$ emission from $\mathrm{Tb}^{3+}$ shows $T_{0.5}=450 \mathrm{~K}$ and that from the ${ }^{5} D_{3}$ level has low quenching temperature of $T_{0.5}=75 \mathrm{~K}^{12}$ and at RT the emission is fully absent. ${ }^{12}$

\section{The niobates}

$\mathrm{LiNbO}_{3}$ From $^{71-73}$ the host excitation is found at $E^{e x}(L T)=4.7 \mathrm{eV}$. The IVCT band for $\mathrm{Pr}^{3+}$ is near $375 \mathrm{~nm}(3.3 \mathrm{eV}) .{ }^{74-76}$ The red emission from the ${ }^{1} D_{2}$ level dominates and only at $77 \mathrm{~K}$ emission from the ${ }^{3} P_{0}$ level of $\mathrm{Pr}^{3+}$ starts to appear. ${ }^{76}$ Emission from the ${ }^{5} D_{3}$ level of $\mathrm{Tb}^{3+}$ is not observed at low temperature, and the ${ }^{5} D_{4}$ emission quenches with $T_{0.5}=200 \mathrm{~K} \cdot{ }^{77}$
$\mathrm{CaNb}_{2} \mathbf{O}_{\mathbf{6}}$ The room temperature host excitation maximum is consistently reported near $265 \mathrm{~nm}(4.65 \mathrm{eV})^{68,69,78,79,81}$ from which $E^{e x}(L T)=4.75 \mathrm{eV}$ is estimated. The excitation maximum of $\mathrm{Eu}^{3+}$ emission is at $272 \mathrm{~nm}(4.55 \mathrm{eV})$ in Ref. 70 which is mostly due to host excitation. $\mathrm{A} \mathrm{Eu}^{3+} \mathrm{CT}$ band cannot be identified. To construct a VRBE scheme one has to use IVCT data for $\mathrm{Pr}^{3+}$ and $\mathrm{Tb}^{3+}$. That of $\mathrm{Pr}^{3+}$ is at $312 \mathrm{~nm}(3.97 \mathrm{eV})$ in Ref. 81 and at $305 \mathrm{~nm}(4.07 \mathrm{eV})$ in Refs. 78 and $79 \mathrm{The}^{3} P_{0}$ emission has $T_{0.5}=380 \mathrm{~K} .{ }^{78}$ The IVCT band for $\mathrm{Tb}^{3+}$ is at $3.95 \mathrm{eV}$ in Refs. 68 and 78, and $T_{0.5}=470 \mathrm{~K}$ for the $\mathrm{Tb}^{3+}$ ${ }^{5} D_{4}$ emission and $120 \mathrm{~K}$ for the ${ }^{5} D_{3}$ emission. ${ }^{78}$ When a VRBE scheme is constructed with this information, the $\mathrm{Eu}^{3+} \mathrm{CT}$-band is predicted near $4.3 \mathrm{eV}$.

$\mathbf{L a N b O}_{4}{ }^{80}$ shows the host excitation maximum at $258 \mathrm{~nm}(4.80 \mathrm{eV})$ for a $100 \%$ pure monoclinic phase sample. Another weaker band at $300 \mathrm{~nm}(4.13 \mathrm{eV})$ was ascribed to defect $\mathrm{NbO}_{6}$-groups. Also we observed (unpublished data) a host excitation maximum at $251 \mathrm{~nm}(4.94 \mathrm{eV})$ and $302 \mathrm{~nm}(4.10 \mathrm{eV})$ in $\mathrm{LaNbO}_{4}: \mathrm{Ce}^{3+}$. We will adopt $E^{e x}(L T)=4.95 \mathrm{eV}$. We also observe (unpublished data) an excitation maximum of $\mathrm{Eu}^{3+}$ at $268 \mathrm{~nm}(4.65 \mathrm{eV})$. The $0.4 \mathrm{eV}$ width of the band seems too narrow for a CT band and probably it is truncated by competing host absorption. We conclude $E^{C T}>4.65 \mathrm{eV}$ and will adopt a value of $4.8 \pm 0.1 \mathrm{eV} .{ }^{3} P_{0}$ emission from $\mathrm{Pr}^{3+}$ is observed at $4.2 \mathrm{~K}$ in Ref. 82. Boutinaud et al..$^{79}$ report a value of $3.84 \mathrm{eV}(322 \mathrm{~nm})$ for the $\mathrm{Pr}^{3+}$ IVCT-band but they also write that the value is not very accurate. We observed (unpublished data) a weak broad excitation band near $330 \mathrm{~nm}(3.75 \mathrm{eV})$ that will here be regarded as the $\mathrm{Pr}^{3+}$ IVCT energy. We also observed $\mathrm{Tb}^{3+}{ }^{5} D_{4}$ and ${ }^{5} D_{3}$ emission at $15 \mathrm{~K}$. Emission from the ${ }^{5} D_{3}$ level is fully quenched at room temperature ${ }^{83}$ and evidence for a Tb ${ }^{3+}$ IVCT band is not available.

$\mathbf{G d N b O}_{4}$. The absorption maximum in undoped $\mathrm{GdNbO}_{4}$ is at $248 \mathrm{~nm}(5.0 \mathrm{eV})$ in Ref. 84. In Ref. 85 an excitation band at $243 \mathrm{~nm}(5.1 \mathrm{eV})$ is present for $\mathrm{Eu}^{3+}$ and for $\mathrm{Tb}^{3+}$ doping that can be attributed to the $\mathrm{NbO}_{4}$ group excitation. We will adopt $E^{e x}(L T)=5.2 \mathrm{eV}$. Upon $\mathrm{Eu}^{3+}$ doping a characteristic about $0.8 \mathrm{~nm}$ FWHM excitation band is observed at $255 \mathrm{~nm}(4.86 \mathrm{eV})$ by ${ }^{86}$ which is also observed at the same wavelength in Ref. 85. It is well separated from the host excitation band and it will be assigned to $E^{C T}=4.86 \mathrm{eV}$. This information is already sufficient to construct a VRBE scheme that predicts the $\mathrm{Pr}^{3+}$ and $\mathrm{Tb}^{3+}$ IVCT bands near $3.9 \mathrm{eV}(318 \mathrm{~nm})$ and $3.7 \mathrm{eV}(335 \mathrm{~nm})$, however, data to confirm this was not found. ${ }^{5} D_{4}$ emission is observed at RT in Ref. 85.

$\mathrm{YNbO}_{4}$. Abundant information is available on this compound. The pure host luminescence excitation maximum varies between $243 \mathrm{~nm}(5.1 \mathrm{eV})$ and $250 \mathrm{~nm}(5.0 \mathrm{eV})$ depending on synthesis conditions. ${ }^{87}$ It is at $251 \mathrm{~nm}(4.95 \mathrm{eV})$ in Ref. 88 , at $243 \mathrm{~nm}$ $(5.1 \mathrm{eV})$ in Ref. 85, and at $242 \mathrm{~nm}(5.10 \mathrm{eV})$ in Ref. 89. We will adopt $E^{e x}(L T)=5.2 \mathrm{eV}$ which is the same as for $\mathrm{GdNbO}_{4}$. The $\mathrm{Eu}^{3+}$ CT-band appears close to the host excitation band. In Ref. 85 for $5 \% \mathrm{Eu}^{3+}$ concentration it is observed resolved at $258 \mathrm{~nm}(4.80$ $\mathrm{eV})$ and in Ref. 89 it is seen as a shoulder band near $260 \mathrm{~nm}(4.75 \mathrm{eV})$. We will adopt $E^{C T}=4.8 \mathrm{eV}$ which is quite similar as in $\mathrm{GdVO}_{4}$. The IVCT excitation band for $\mathrm{Pr}^{3+}$ is near $306 \mathrm{~nm}(4.05 \mathrm{eV})$ and for $\mathrm{Tb}^{3+}$ near $311 \mathrm{~nm}(4.00 \mathrm{eV}){ }^{40,78}$ These values for the IVCT band are consistent with the VRBE scheme constructed with the $\mathrm{Eu}^{3+}$ CT-band energy and $E^{e x}$. The emission from the ${ }^{3} P_{0}$ level of $\mathrm{Pr}^{3+}$ already starts to quench below RT and at $370 \mathrm{~K}$ emission has dropped to $50 \%$ of the RT value indicating that $T_{0.5}<370$ $\mathrm{K}$. The emission from the ${ }^{5} D_{4}$ level dominates and is quenched with $T_{0.5}=460 \mathrm{~K}$ and emission from ${ }^{5} D_{3}$ emission is not observed at RT in Ref. 78. In Ref. $87{ }^{5} D_{3}$ emission is weakly observed at RT.

LuNbO 4 Like in $\mathrm{GdNbO}_{4}$ and $\mathrm{YNbO}_{4}$ a band is observed near $243 \mathrm{~nm}(5.1 \mathrm{eV})$ in the excitation spectra of $\mathrm{Eu}^{3+}$ and $\mathrm{Tb}^{3+}$ doped $\mathrm{LuNbO}_{4}$ that might be attributed to the host excitation band. ${ }^{85}$ For undoped $\mathrm{LuNbO}_{4}$ a RT excitation maximum of the host emission is reported at $266 \mathrm{~nm}(4.66 \mathrm{eV})$ in Ref. 90 suggesting $E^{e x}(L T)$ of about $4.8 \mathrm{eV}$. The same authors find the excitation maximum for $\mathrm{Eu}^{3+}$ emission at $268 \mathrm{~nm}(4.65 \mathrm{eV})$. On the other hand in Ref. 85 the CT-band can also be located at $245 \mathrm{~nm}(5.06 \mathrm{eV})$. At this stage the available information is not conclusive and we will assume the same $E^{e x}$ and $E^{C T}$ as in $\mathrm{YNbO}_{4}$. Information on $\mathrm{Pr}^{3+}$ was not found, and $\mathrm{Tb}^{3+}$ shows emission from the ${ }^{5} D_{4}$ level at RT. ${ }^{85}$

\section{The tungstates}

BaWO $_{4}$. The energy of the RT fundamental absorption onset is at $5.26 \mathrm{eV}$ in Refs. 71 and 95, the ultraviolet absorbance spectrum reaches its maximum at $5.6 \mathrm{eV}$ in Ref. 96, and from low temperature vacuum ultraviolet excitation studies in Ref. 48 the host exciton maximum is at $5.7 \pm 0.2 \mathrm{eV}$. In this work we will adopt the value of 5.6 $\mathrm{eV}$ for $E^{e x}(L T)$. The CT excitation maximum of $\mathrm{Eu}^{3+}$ emission is at $258 \mathrm{~nm}(4.80 \mathrm{eV})$ in Ref. 104 for $1 \%$ doping level, at $271 \mathrm{~nm}(4.58 \mathrm{eV})$ in Ref. 98 for $15 \%$ Eu doping, at $280 \mathrm{~nm}(4.43 \mathrm{eV})$ in Ref. 51 , at $283 \mathrm{~nm}(4.38 \mathrm{eV})$ in Ref. 99 for $1-9 \% \mathrm{Eu}^{3+}$. We conclude that $E^{C T}=4.45 \mathrm{eV}$ which is the same as in $\mathrm{SrWO}_{4}$. Adding $\mathrm{Pr}^{3+}$ creates absorption in the $4.2-5.0 \mathrm{eV}$ region. ${ }^{96}$ It is just below the onset of the host absorption and it suggests a $\mathrm{Pr}^{3+}$ IVCT band near $4.6 \pm 0.2 \mathrm{eV}$. In $\mathrm{BaWO}_{4}$ the $\mathrm{Tb}^{3+}$ excitation maximum is at $236 \mathrm{~nm}(5.25 \mathrm{eV})$ in Ref. 100. It can be partly the onset of the host excitation and partly the $\mathrm{Tb}^{3+} 4 \mathrm{f}-5 \mathrm{~d}$ excitation. A weak tail extending to about $290 \mathrm{~nm}$ might be from the expected IVCT band. In Ref. 51 the $\mathrm{Tb}^{3+}$ excitation maximum is at $272 \mathrm{~nm}(4.55 \mathrm{eV})$ where the IVCT band is expected. At room temperature emission from both ${ }^{5} D_{3}$ and ${ }^{5} D_{4}$ is observed.

$\mathrm{SrWO}_{4}$. The RT fundamental absorption onset is at $248 \mathrm{~nm}(5.08 \mathrm{eV})$ in Ref. 95 , and the RT host excitation maximum is reported at $252 \mathrm{~nm}(4.92 \mathrm{eV})$ in Ref. 101. Vacuum ultraviolet studies in Ref. 48 shows that the intrinsic exciton creation peak is around 5.5 
$\pm 0.2 \mathrm{eV}$. We will adopt $5.35 \mathrm{eV}$ for $E^{e x}(L T)$ in this work. Excitation spectra of $\mathrm{Eu}^{3+}$ emission shows the CT-band at $286 \mathrm{~nm}(4.35 \mathrm{eV})$ in Ref. 102, at $279 \mathrm{~nm}(4.44 \mathrm{eV})$ in Ref 103 , at $271 \mathrm{~nm}(4.58 \mathrm{eV})$ in Ref. 104, at $281 \mathrm{~nm}(4.41 \mathrm{eV})$ in Ref. 101, at $278 \mathrm{~nm}(4.46$ $\mathrm{eV})$ in Ref. 105, and at $280 \mathrm{~nm}(4.43 \mathrm{eV})$ in Ref. 105 . Altogether we conclude that $E^{C T}$ is near $280 \mathrm{~nm}$ or $4.45 \mathrm{eV}$ which is the same as in $\mathrm{BaWO}_{4}$. With $\mathrm{Pr}^{3+}$ doping intense emission lines from the ${ }^{3} P_{0}$ level are observed at $\mathrm{RT}^{106}$ but information to derive the IVCT band energy was not found. The excitation maximum of ${ }^{5} D_{4}$ emission is near 260 $\mathrm{nm}(4.8 \mathrm{eV})$ in Ref. 107. It is at lower energy than that for host exciton creation and may suggest the presence of an IVCT band.

CaWO $_{4}$. The RT fundamental absorption onset is at $251 \mathrm{~nm}(4.94 \mathrm{eV})$ in Ref. 95 which is consistent with the $15 \mathrm{~K}$ vacuum ultraviolet excitation studies in Ref. 48 where the exciton peak is at $5.2 \mathrm{eV} \pm 0.2 \mathrm{eV}$. Undoped $\mathrm{CaWO}_{4}$ shows a broad $430 \mathrm{~nm}$ emission band at RT with an excitation maximum at $243 \mathrm{~nm}(5.1$ eV). ${ }^{97,104,108}$ In Ref. 109 the excitation maximum is at $238 \mathrm{~nm}(5.2 \mathrm{eV})$. In this work we will adopt $E^{e x}(L T)=5.25 \mathrm{eV}$. The $\mathrm{Eu}^{3+} \mathrm{CT}$-band is at $261 \mathrm{~nm}(4.75 \mathrm{eV})$ in Ref. 102 , at $267 \pm 10 \mathrm{~nm}(4.64 \mathrm{eV})$ in Ref. 110 shifting to $286 \mathrm{~nm}(4.35 \mathrm{eV})$ when $10 \% \mathrm{Li}$ is added for charge compensation. It is at $266 \mathrm{~nm}(4.66 \mathrm{eV})$ in Ref. 104, at $262 \mathrm{~nm}(4.73 \mathrm{eV})$ in Ref. 97, and at $268 \mathrm{~nm}(4.62 \mathrm{eV})$ in Ref. 111. We conclude that $E^{C T}=4.7 \pm 0.1 \mathrm{eV}$. The VRBE scheme then predicts the $\mathrm{Pr}^{3+}$ IVCT band at $4.4 \mathrm{eV}(282$ $\mathrm{nm})$. The excitation maximum of $\mathrm{Pr}^{3+}$ emission is at $270 \mathrm{~nm}(4.59 \mathrm{eV})$ in Ref. 112 and at $254 \mathrm{~nm}(4.88 \mathrm{eV})$ in Ref. 113, but it is not certain at all whether these excitations are related to the IVCT band. They can equally well be related with the host exciton or near defect exciton creation bands. In any case the emission from the ${ }^{3} P_{0}$ level dominates at RT. ${ }^{112,113}$ The emission from $\mathrm{Tb}^{3+}$ is very stable and $T_{0.5}>600 \mathrm{~K}$ for the ${ }^{5} D_{4}$ emission in $\mathrm{CaWO}_{4}$ and the emission from ${ }^{5} D_{4}$ has $T_{0.5}=450 \mathrm{~K} .{ }^{12}$

$\mathrm{PbWO}_{4}$. The energy of host exciton creation at low temperature $E^{e x}(L T)$ is found at $4.35 \mathrm{eV}$ from. ${ }^{48,91,92}$ With $\mathrm{Pr}^{3+}$ doping an additional broad band is observed between $300 \mathrm{~nm}$ and $360 \mathrm{~nm}$ and peaking near $335 \mathrm{~nm}(3.70 \mathrm{eV})$ which is too low energy to attribute to $4 \mathrm{f}-5 \mathrm{~d}$ transitions. Instead an IVCT band is much more likely. The emission from ${ }^{3} P_{0}$ does not yet show any evidence for thermal quenching at room temperature and $T_{0.5}$ is then estimated $>350 \mathrm{~K}$. With $\mathrm{Tb}^{3+}$ a band is observed near $330 \mathrm{~nm}(3.75 \mathrm{eV})$ at energy below $E^{\text {ex }} .{ }^{93}$ Like for $\mathrm{Pr}^{3+}$ we attribute this band to the IVCT band..$^{93,94}$ report ${ }^{5} D_{4}$ emission at room temperature and also weak emission from ${ }^{5} D_{3}$ is observed.

\section{The tantalates}

The M-type rare earth tantalates with Gd, Y, and Lu have the fergusonite structure which can be considered as a distorted scheelite structure and $\mathrm{Ta}^{5+}$ is tetrahedrally coordinated. There also exists a low temperature phase (M'-type) with octahedral coordinated $\mathrm{Ta}^{5+} .114,115$ On the level of accuracy of the VRBE schemes presented in this work we will not make a distinction between the two modifications and the schemes apply approximately to both.

$\mathbf{L a T a O}_{4}$. Diffuse reflection spectra of undoped $\mathrm{LaTaO}_{4}$ reaches a maximum near $250 \mathrm{~nm}(4.96 \mathrm{eV}){ }^{116,117} \mathrm{~A}$ vacuum ultra violet study at $10 \mathrm{~K}$ on the $\mathrm{Pr}^{3+}$ emission shows an excitation band at $242 \mathrm{~nm}(5.10 \mathrm{eV})$, and in this work we will attribute this to $E^{e x}(L T)$. The $\mathrm{Eu}^{3+}$ CT-band is at $272 \mathrm{~nm}(4.55 \mathrm{eV})$ in Ref. 118 at $1 \% \mathrm{Eu}^{3+}$ doping, at $282 \mathrm{~nm}$ $(4.40 \mathrm{eV})$ in Ref. 119 at 3\% doping, at $297 \mathrm{~nm}(4.18 \mathrm{eV})$ in Ref. 120 at 5-10\% doping, and at $307 \mathrm{~nm}(4.05 \mathrm{eV})$ in Ref. 121 upon doping with $25 \%$ and $40 \% \mathrm{Eu}^{3+}$. Apparently the CT-maximum redshifts with higher Eu concentration and here we will adopt the low concentration value of $4.55 \mathrm{eV}$ for $E^{C T}$. However, one may not exclude the possibility that the $\mathrm{Eu}^{3+} \mathrm{CT}$-band is cut-off on the short wavelength side by competing host absorption, and in that case the CT-maximum can be located near $4.7 \mathrm{eV}$. With the chosen parameters, the VRBE scheme predicts the IVCT bands for $\mathrm{Pr}^{3+}$ and $\mathrm{Tb}^{3+}$ near $4.0 \mathrm{eV}(310 \mathrm{~nm}) . \mathrm{A}$ clear shoulder band near $270 \mathrm{~nm}(4.6 \mathrm{eV})$ is observed in the excitation spectrum of $\mathrm{Pr}^{3+}$ emission in Ref. 122 and it may be the IVCT band, however, this is not consistent with the prediction. Emission from the ${ }^{3} P_{0}$ and ${ }^{1} D_{2}$ level is observed at $10 \mathrm{~K}$ and $300 \mathrm{~K}$ in a ratio that remains fixed which suggests no significant quenching of the ${ }^{3} P_{0}$ emission and we tentatively assume $\mathrm{T}_{0.5}>350 \mathrm{~K}$. The excitation maximum of $\mathrm{Tb}^{3+}$ emission is at $270 \mathrm{~nm}(4.6 \mathrm{eV})^{119}$ and like for $\mathrm{Pr}^{3+}$ this could be the IVCT band but again it is not consistent with the scheme. The luminescence quantum efficiency of $\mathrm{Tb}^{3+}$ emission at $3 \%$ doping level is $20 \%$ whereas for $\mathrm{GdTaO}_{4}$ and $\mathrm{LuTaO}_{4}$ it is $70 \% .{ }^{119}$ This suggest that $T_{0.5}<300 \mathrm{~K}$.

$\mathrm{GdTaO}_{4}$. Vacuum ultraviolet spectroscopy at $20 \mathrm{~K}$ shows the host emission excitation maximum at $217 \mathrm{~nm}(5.71 \mathrm{eV})^{123}$ and at $209 \mathrm{~nm}(5.93 \mathrm{eV}){ }^{124}$ Also with Xenon lamp spectroscopy, the RT host excitation maximum is observed in the $5.75 \mathrm{eV}$ to $5.95 \mathrm{eV}$ energy region ${ }^{118,119,125-128}$ We will adopt in this work $E^{e x}(L T)=5.80 \pm 0.1 \mathrm{eV}$. The $\mathrm{Eu}^{3+} \mathrm{CT}$ in $\mathrm{GdTaO}_{4}$ is consistently reported near $248 \mathrm{~nm}(5.0 \mathrm{eV}) .{ }^{118,123,124,126,128}$ With these parameters the VRBE scheme predicts the IVCT bands for $\mathrm{Pr}^{3+}$ and $\mathrm{Tb}^{3+}$ near $4.2 \mathrm{eV}(295 \mathrm{~nm})$. Noto et al. ${ }^{122}$ studied $\mathrm{Pr}^{3+}$ in $\mathrm{GdTaO}_{4}$ with VUV-techniques and a clear excitation maximum is observed at $265 \mathrm{~nm}(4.68 \mathrm{eV})$ that can be attributed to $4 \mathrm{f}-5 \mathrm{~d}$ transitions. Emission from ${ }^{3} P_{0}$ and ${ }^{1} D_{2}$ is stable up to at least RT. Excitation spectra of $\mathrm{Tb}^{3+}$ emission shows a clear maximum around $260 \mathrm{~nm}(4.77 \mathrm{eV}) .{ }^{119,125,127,129}$ It was ascribed to the IVCT state in Ref. 119 but in Ref. 129 it was re-assigned to the spin allowed 4f-5d transition in $\mathrm{Tb}^{3+}$. A weak band at $295 \mathrm{~nm}(4.20 \mathrm{eV})$ was assigned to the spin forbidden transition. ${ }^{129}$ The energy difference between the spin allowed and spin forbidden transition of $0.57 \mathrm{eV}$ seems too small and considering the prediction from the
VRBE scheme an IVCT band is then more likely. For $3 \% \mathrm{~Tb}^{3+}$ in $\mathrm{GdTaO}_{4}$ at RT $70 \%$ quantum efficiency is reported in Ref. 119 and emission from both the ${ }^{5} D_{3}$ and the ${ }^{5} D_{4}$ level is observed. ${ }^{114,125,129} \mathrm{~A}$ high quantum efficiency at room temperature implies that $T_{0.5}$ must be well above RT.

$\mathrm{YTaO}_{4}$. The host excitation maximum is reported at $215 \mathrm{~nm}(5.75 \mathrm{eV})$ and in this work a value of $5.80 \pm 0.1 \mathrm{eV}$ will be used for $E^{e x}(L T)$. The $\mathrm{Eu}^{3+} \mathrm{CT}$ band is at 238 $\mathrm{nm}(5.2 \mathrm{eV})$ in Ref. 89 at $242 \mathrm{~nm}(5.12 \mathrm{eV})$ in Ref. 118 at $248 \mathrm{~nm}(5.0 \mathrm{eV})$ in Ref. 119. We will adopt a value of $5.10 \mathrm{eV}$ for $E^{C T}$ in this work. The first $\operatorname{Pr}^{3+}$ emission excitation band is consistently observed near $271 \mathrm{~nm}(4.57 \mathrm{eV})$ in Refs. 40, 88, and 122 and should be attributed to the first $4 \mathrm{f}-5 \mathrm{~d}$ transition. $5 \mathrm{~d}-4 \mathrm{f}$ emission is not observed for $\mathrm{Pr}^{3+}$ and only emission lines from the ${ }^{3} P_{0}$ and ${ }^{1} D_{2}$ levels appear in a ratio that does not change between $10 \mathrm{~K}$ and RT. It indicates that the quenching temperature $T_{0.5}$ for both emissions are well above RT. The VRBE scheme constructed with above parameters now predicts the $\mathrm{Pr}^{3+}$ IVCT band near $4.15 \mathrm{eV}(300 \mathrm{~nm})$. Indeed an asymmetry on the long wavelenth side of the $4 \mathrm{f}-5 \mathrm{~d}$ transition in Ref. 40 might indicate such IVCT. $\mathrm{Tb}^{3+}$ has the first excitation maximum at $261 \mathrm{~nm}(4.75 \mathrm{eV})$ in Ref. 89, at $264 \mathrm{~nm}(4.70 \mathrm{eV})$ in Ref. 119, and at 273 $\mathrm{nm}(4.54 \mathrm{eV})$ in Ref. 40 . The average of $4.66 \mathrm{eV}$ is about the same as in $\mathrm{GdTaO}_{4}$ and is attributed to the first spin allowed $4 \mathrm{f}-5 \mathrm{~d}$ transition. A long wavelength tail between $300 \mathrm{~nm}$ and $340 \mathrm{~nm}$ to the $273 \mathrm{~nm}$ excitation peak of $\mathrm{Tb}^{3+}$ emission in Ref. 40 may, like for $\mathrm{Pr}^{3+}$, be related to the IVCT band consistent with the VRBE scheme. Blasse and Bril ${ }^{119}$ reported a 70\% high quantum efficiency at RT for the $\mathrm{Tb}^{3+}$ emission together with a very high quenching temperature of $T_{0,5}=750 \mathrm{~K}$. Under X-ray excitation, the emission from the $\mathrm{Tb}^{3+}{ }^{5} \mathrm{D}_{3}$ level is observed at $\mathrm{RT}$ for $1 \%$ doped $\mathrm{YTaO}_{4} .{ }^{114}$

$\mathrm{LuTaO}_{4}$. Xenon lamp excitation based data show that the host excitation maximum in $\mathrm{LuTaO}_{3}$ is near $218 \mathrm{~nm}(5.7 \mathrm{eV})$ in Refs. 118, 130, and 131 This is the same as observed for $\mathrm{GdTaO}_{4}$ and $\mathrm{YTaO}_{4}$ with Xenon lamp excitation and hence the same value for $E^{e x}(L T)=5.80 \mathrm{eV}$ will be used. The CT-band for $1 \% \mathrm{Eu}^{3+}$ doping is at $240 \mathrm{~nm}$ $(5.15 \mathrm{eV})$ in Refs. 118 and 131, and at $250 \mathrm{~nm}(4.96 \mathrm{eV})$ in Ref. 84 for $5 \% \mathrm{Eu}^{3+}$. In this work we will adopt $E^{C T}=5.15 \mathrm{eV}$. With $10 \% \mathrm{~Tb}^{3+}$ strong emission from ${ }^{5} D_{4}$ is observed at room temperature with an excitation band near $260 \mathrm{~nm}(4.77 \mathrm{eV})$ which is attributed to the first spin allowed 4f-5d excitation of $\mathrm{Tb}^{3+}$. Under X-ray excitation ${ }^{3} P_{0}$ emission is observed at RT, ${ }^{118,130}$ and also under X-ray excitation emission from the ${ }^{5} D_{3}$ and ${ }^{5} D_{4}$ levels of $\mathrm{Tb}^{3+}$ are observed at RT. ${ }^{130}$

$\mathrm{ScTaO}_{4}$. There appears to be not much data on the spectroscopy of the lanthanides in $\mathrm{ScTaO}_{4}$. The RT excitation spectrum of Eu${ }^{3+}$ emission shows the $\mathrm{CT}$ band at $238 \mathrm{~nm}$ $(5.20 \mathrm{eV})$ for $1 \%$ doping in Ref. 118 and a weak band on top of it at $223 \mathrm{~nm}(5.6 \mathrm{eV})$ which might be related to the host excitation band. Tb ${ }^{3+}$ shows emission from the ${ }^{5} \mathrm{D}_{4}$ level at room temperature with a broad excitation band around $292 \mathrm{~nm}(4.24 \mathrm{eV})$ which may be due to either the IVCT transitions or the first spin forbidden 4f-5d excitation band of $\mathrm{Tb}^{3+} .{ }^{132}$ With the lack of further data only a tentative VRBE scheme can be made. We will adopt $E^{e x}(L T)=5.8 \mathrm{eV}$, i.e., the same value as for $\mathrm{Gd}$-, Y-, and $\mathrm{LuTaO}_{4}$, and $E^{C T}=5.2 \mathrm{eV}$.

\section{References}

1. R. van de Krol, Yongqi Liang, and J. Schoonman J. Mat. Chem., 18, 2311 (2008)

2. P. Dorenbos, A. J. J. Bos, N. R. J. Poolton, and Fangtian You, J. Lumin., 133, 45 (2013).

3. P. Dorenbos Chemistry of Materials, 17, 6452 (2005).

4. P. Dorenbos Phys. Rev., B 85, 165107 (2012).

5. P. Dorenbos J. Phys.: Condens. Matter, 25, 225501 (2013).

6. P. Dorenbos Phys. Rev., B 87, 035118 (2013).

7. P. Dorenbos ECS Journal of Solid State Science and Technology, 3, R19 (2014).

8. P. Dorenbos J. Lumin., 136, 122 (2013).

9. A. L. Allred J. Inorg. Nucl. Chem., 17, 215 (1961).

10. The data were retrieved from the website http://www.webelements.com/.

11. P. Dorenbos, A. H. Krumpel, E. van der Kolk, P. Boutinaud, M. Bettinelli, and E. Cavalli Optical Materials, 32, 1681 (2010).

12. E. Cavalli, P. Boutinaud, R. Mahiou, M. Bettinelli, and P. Dorenbos Inorganic Chemistry, 49, 4916 (2010)

13. A. H. Krumpel, E. van der Kolk, P. Dorenbos, P. Boutinaud, E. Cavalli, and M. Bettinelli, Mater. Science and Eng., B 146, 114 (2008).

14. A. H. Krumpel, E. van der Kolk, E. Cavalli, P. Boutinaud, M. Bettinelli, and P. Dorenbos J. Phys. Cond. Mat., 21, 115503 (2009).

15. P. Dorenbos J. Lumin., 111, 89 (2005).

16. I. Pelant and J. Valenta, Luminescence Spectroscopy of Semiconductors, DOI: 10.1093/acprof:oso/9780199588336.001.0001, Published to Oxford Scholarship Online, (2012).

17. E. Cavalli, P. Boutinaud, M. Bettinelli, and P. Dorenbos J. Solid State Chem., 181, 1025 (2008).

18. E. G. Rogers and P. Dorenbos J. Lumin., 153, 40 (2014).

19. T. Kyomen, R. Sakamoto, N. Sakamoto, S. Kunugi, and M. Itoh Chem. Mater, 17, $3200(2005)$

20. P. Boutinaud, L. Sarakha, R. Mahiou, E. Cavalli, M. Bettinelli, P. Dorenbos, and R. Mahiou J. Phys. D: Appl. Phys., 42, 045106 (2009).

21. Y. Katayama, J. Ueda, and S. Tanabe J. Lumin., 148, 290 (2014).

22. S. Okamoto, K. Tanaka, and H. Yamamoto Int. Journ. Modern Phys., B 15, 3924 (2001).

23. S. Okamoto, H. Kobayashi, and H. Yamamoto J. Appl. Phys., 86, 5594 (1999). 
24. P. Dorenbos J. Lumin., 151, 224 (2014).

25. E. G. Rogers and P. Dorenbos, ECS Journal of Solid State Science and Technology, submitted May 2014.

26. Guocong Liu, Xuechen Duan, Haibin Li, Hui Dong, and Ligang Zhu J. Cryst. Growth., 310, 4689 (2008)

27. Guocong Liu, Xuechen Duan, Haibin Li, and Hui Dong Mat. Chem. Phys., 115, 165 (2009).

28. Shuai Zhang, Li Wang, Hongrui Peng, Guicun Li, and Kezheng Chen Materials Chemistry and Physics, 123, 714 (2010).

29. Wook Sung Park, Kyoung Hyun Yang, Won Jong Chung, Yeqing Chen, Kee Byung Moon, Chun Byung Choi, Hyun Jung Jeong, and Jung Hwan Kim, Physica, $B$ 405, 4040 (2010).

30. P. Boutinaud, R. Mahiou, E. Cavalli, and M. Bettinelli Chem. Phys. Lett., 418, 185 (2006).

31. M. Anitha, P. Ramakrishnan, A. Chatterjee, G. Alexander, and H. Singh Appl. Phys. A, 74, 153 (2002).

32. Yinglin Yan, Juan Wang, Zhengxin Lu, Bing Ren, Liangliang Wang, and Yunhua Xu Powder Technology, 249, 475 (2013).

33. Bo Liu, Chaoshu Shi, Qingli Zhang, and Yonghu Chen J. Alloys Comp., 333, 215 (2002).

34. Amurisana Bao, Hua Yang, Chunyan Tao, Ying Zhang, and Lili Han Journal of Luminn., 128, 60 (2008).

35. E. Pinel, P. Boutinaud, and R. Mahiou J. Alloys and Comp., 374, 165 (2004).

36. P. Boutinaud, R. Mahiou, E. Cavalli, and M. Bettinelli, J. Lumin. 122-123, 430 (2006).

37. P. Boutinaud, R. Mahiou, E. Cavalli, and M. Bettinelli J. Applied Physics, 96, 4923 (2004).

38. S. Mahlik, M. Grinberg, E. Cavalli, M. Bettinelli, and P. Boutinaud J. Phys. Cond. Matter, 21, 105401 (2009)

39. Youfa Wang, Shuai Wang, Zhouli Wu, Wenrun Li, and Yongfeng Ruan J. Alloys and Comp., 551, 262 (2013).

40. P. Boutinaud, P. Putaj, R. Mahiou, E. Cavalli, and A. Speghini Spectroscopy Letters, 40, 209 (2007).

41. G. Blasse and A. Bril Philips Res. Repts., 22, 481 (1967).

42. Juan Li, Jun Yong Wu, and Makoto Kuwabara Key Engineering Materials, 301, 197 (2006).

43. L. G. J. de Haart, A. J. de Vries, and G. Blasse Mat. Res. Bull., 19, 817 (1984).

44. E. A. V. Ferri, J. C. Sczancoski, L. S. Cavalcante, E. C. Paris, J. W. M. Espinosa, A. T. de Figueiredo, P. S. Pizani, V. R. Mastelaro, J. A. Varela, and E. Longo Mate rials Chemistry and Physics, 117, 192 (2009).

45. Zhang Jian, Yin Jing, Llu Panpan, Gao Bin, and Bie Lijian J. of Rare Earths, 30, 1009 (2012)

46. Dong Ick Shin, Hyunju Chang, Kyu Joung Park, Hwa Cheong-Han, and Dong Hee Park Jpn. J. Appl. Phys., 42, 5807 (2003).

47. L. S. Cavalcante, J. C. Sczancoski, R. L. Tranquilin, M. R. Joya, P. S. Pizani, J. A. Varela, and E. Longo J.Phys. Chem. Solids, 69, 2674 (2008).

48. V. N. Kolobanov, I. A. Kamenskikh, V. V. Mikhailin, I. N. Shpinkov, D. A. Spassky, B. I. Zadneprovsky, L. I. Potkin, and G. Zimmerer, Nucl. Instr. and Meth., A $\mathbf{4 8 6}$, 496 (2002).

49. Xianghong He, Mingyun Guan, Zhongchun Li, Tongming Shang, Ning Lian, and Quanfa Zhou J. Am. Ceram. Soc., 94, 2483 (2011).

50. Guang Jia, Cuimiao Huang, Lanfen Li, Chunzheng Wang, Xingbang Song, Le Song, Zheng Li, and Shiwen Ding Opt. Mater, 35, 285 (2012).

51. Jintai Lin, Zhi Zeng, Qianmin Ma, Qianming Wang, and Yanfen Zhang Energy, 64, 551 (2014).

52. I. L. V. Rosa, A. P. A. Marques, M. T. S. Tanaka, D. M. A. Melo, E. R. Leite, E. Longo, and J. A. Varela J. Fluoresc., 18, 239 (2008).

53. P. Yang, C. Li, W. Wang, Z. Quan, A. Gai, and J. Lin J. Solid Sate Chem., 182, 2510 (2009).

54. Xuyong Yang, Jie Liu, Hong Yang, XiBin Yu, Yuzhu Guo, Yongqin Zhou, and Jieyu Liu J. Mater. Chem., 19, 3771 (2009).

55. J. C. Sczancoski, L. S. Cavalcante, M. R. Joya, J. A. Varela, P. S. Pizani, and E. Longo Chem. Engin. J., 140, 632 (2008).

56. Na Niu, Piaoping Yang, Wenxin Wang, Fei He, Shili Gai, Dong Wang, and Jun Lin Mat. Res. Bul., 46, 333 (2011).

57. Li Xu, Yang Xhiping, Guan Li, Guo Qinglin, Huai Sufang, and Li Panlei J. Rare Earths, 25, 706 (2007)

58. A. P. A. Marques, M. T. Tanaka, E. Longo, E. R. Leite, and I. L. V. Rosa J. Fluoresc., 2, 893 (2011)

59. Fei Yun-Liu, Hua Shen-Dai, Nong Yi-Lu, and Hua Hui-Min Powder Technology, 221, 412 (2012)

60. Wen Wu, Yawen Xuan, nong Jiang Yin, and Jianpin Xie, Res. Chem. Intermed. DOI

61. Jie Liu, Hongzhou Lian, and Chunshan Shi Opt. Mater., 29, 1591 (2007).

62. J. A. Groenink, C. Hakvoort, and G. Blasse phys. stat. sol. (a), 54, 477 (1979)

63. Fang Lei and Bing Yan J. Sol. State Chem., 181, 855 (2008).

64. Sheng Yu, Zhoubin Lin, Lizhen Zhang, and Guofu Wang Cryst. Growth and Design, 7, 2397 (2007).

65. Fang Zhu, Zhisong Xiao, Feng Zhang, Lu Yan, and Anping Huang J. Lumin., 131, $22(2011)$

66. E. Cavalli, F. Angiuli, P. Boutinaud, and R. Mahiou J. Solid State Chem., 185, 136 (2012).

67. Xu Li, Xhiping Yang, Li Guan, Jianxin Guo, Ying Wang, and Qinglin Guo J. Alloys and Comp., 478, 684 (2009).

68. C. Pedrini, A. Belsky, K. V. Ivanovskikh, A. G. Petrosyan, R. V. Sargsyan, and I. Kamenskikh Chem. Phys. Lett., 515, 258 (2011).
69. Ru Zhou, Xiantao Wei, Shan Huang, Yonghu Chen, and Min Yin J. Alloys. Comp., 537, 123 (2012).

70. Huang Junlia, Zhou Liya, He Xipua, and Gong Fuzhong Chin. J. Chem., 29, 441 (2011)

71. G. Blasse and A. Bril J. Electrochem. Soc.: Sol. State Sci., 115, 1067 (1968)

72. Myeongkyu Lee, Soo Ki-Lim, Kyun Sun-Lee, Thai Van-Pham, Kenji Kitamura, and Shunji Takekawa, J. Lumin., 102-103, 644 (2003).

73. M. H. J. Emond, M. Wiegel, and G. Blasse, Mat. Res. Bull. 28 (1993) 1025.

74. M. Grinberg Optical Mater., 28, 26 (2006).

75. Cz. Koepke, K. Wisniewski, D. Dyl, M. Grinberg, and M. Malinovski Optical Materials, 28, 137 (2006)

76. P. Boutinaud, L. Sarakha, and R. Mahiou J. Phys.: Condens. Matter, 21, 025901 (2009).

77. W. Ryba-Romanovski, S. Golab, W. A. G. Dominiak-Dzik, M. N. Palatnikov, and N. V. Sidorov Appl. Phys. Lett., 78, 3610 (2001)

78. P. Boutinaud, E. Cavalli, and M. Bettinelli, J. Phys. Cond. Matter, 19, 386230 (2007)

79. P. Boutinaud, E. Pinel, M. Oubaha, R. Mahiou, E. Cavalli, and M. Bettinelli Optical Materials, 28, 9 (2006)

80. Y. J. Hsiao, T. H. Fang, Y. S. Chang, Y. H. Chang, C. H. Liu, L. W. Ji, and W. Y. Jywe Journal of Luminescence, 126, 866 (2007).

81. S. Mahlik, M. Grinberg, A. A. Kaminskii, M. Bettinelli, and P. Boutinaud J. Lumin., 129, 1219 (2009).

82. C. de Mello Donega, A. Meijerink, and G. Blasse J. Lumin., 62, 189 (1994).

83. B. Yan and X. Z. Xiao Opt. Mater, 28, 498 (2006).

84. Ying Lu, Xinghua Tang, Liushui Yan, Kexin Li, Xiaoming Liu, Mengmeng Shang, Chunxia Li, and Jun Lin J. Phys. Chem. C, 117, 21972 (2013).

85. Xiuzhen Xiao and Bing Yan J. Non-Cryst. Solids, 351, 3634 (2005).

86. Jintai Lin, Zhan Zhou, and Qianming Wang Materials Research Bulletin, 48, 277 (2013).

87. Yuanyuan Zhou, Qian Ma, Mengkai Lu, Zifeng Qiu, and Aiyu Zhang J. Phys. Chem. C, 112, 19901 (2008)

88. W. J. Schipper, M. F. Hoogendorp, and G. Blasse J. of Alloys and Compounds, 202, 283 (1993)

89. M. Nazarov, E. J. Popovici, I. Arellano, and D.Y. Noh Moldavian J. of the Physical Sciences, 7, 433 (2008).

90. S. K. Mahesh, P. Prabhakar Rao, T. L. Francis, V. R. Reshmi, and P. Koshy Material Letters, 120, 115 (2014).

91. F. M. Pontes, M. A. M. A. Maurera, A. G. Souza, E. Longo, E. R. Leite, R. Magnani, M. A. C. machado, P. S. Pizani, and J. A. Varela J. European Ceramic Society, 23 $3001(2003)$

92. Yanlin Huang, Taiju Tsuboi, and Jin Hyo Seo J. Phys. Chem. A, 112, 5839 (2008).

93. A. Nosenko, L. Kostyk, and L. Koslovs'ka Journal of Luminescence, 90, 49 (2000).

94. M. Nikl, P. Bohacek, E. Mihokova, N. Solovieva, M. Martini, A. Vedda, P. Fabeni, G. P. Pazzi, M. Kobayashi, Mi. Ischii, Y. Usuki, and D. Zimmerman J. Cryst. Growth, 229, 312 (2001).

95. R. Lacomba-Perales, J. Ruiz-Fuertes, D. Errandonea, D. Martinez-Garcia, and A. Segura Europhysics Letters, 83, 37002 (2008).

96. L. S. Cavalcante, F. M. C. Batista, M. A. P. Almeida, A. C. Rabelo, I. C. Nogueira N. C. Batista, J. A. Varela, M. R. M. C. Santos, E. Longob, and M. Siu Li RSC Advances, 2, 6438 (2012).

97. wen Feng-Kang, hua Yi-Hun, Li Chen, Xiao-juan Wang, yi Hao-Wu, and fei Zhong-Mu Journal of Luminescence, 135, 113 (2013)

98. Jinsheng Liao, Bao Qiu, Rui He-Wen, Yong Li, Ruijin Hong, and Hangying You $J$ Mater. Sci., 46, 1184 (2011)

99. L. Krishna Bharat and Su Jae Yu Journal of Nanoscience and Nanotechnology, 13 8239 (2013)

100. H. K. Li, Z. L. Wang, S. J. Xu, and J. H. Hao J. Electrochem. Soc., 156, J112 (2009).

101. Guohua Jia, Cuifang Wang, and Shiqing Xu J. Phys. Chem. C, 114, 17905 (2010).

102. B. S. Barros, A. C. deLima, Z. R. daSilva, D. M. A. Melo, and S. Alves-Jr Journal of Physics and Chemistry of Solids, 73, 635 (2012).

103. Zhengua Ju, Ruiping Wei, Xiuping Gao, Weisheng Liu, and Chaoran Pang Opt. Mater., 33, 909 (2011).

104. wen Feng-Kang, hua Yi-Hun, Li Chen, Xiao-juan Wang, yi Hao-Wu, and fei Zhong-Mu Journal of Luminescence, 135, 113 (2013)

105. P. F. S. Pereira, A. P. de Moura, I. C. Nogueira, M. V. S. Lima, E. Longo, P. C. de Sousa Filho, O. A. Serra, E. J. Nassar, and I. L. V. Rosa Journal of Alloys and Compounds, 526, 11 (2012)

106. G. Jia, H. Wang, X. Lu, Z. You, J. Li, Z. Zhu, and C. Tu, Appl. Phys., B90, 497 (2008).

107. Jinshen Liao, Bao Qiu, Herui Wen, Jinglin Chen, and Weixiong You Mat. Res. Bull., 44, 1863 (2009)

108. M. L. Pang, J. Lin, S. B. Wang, M. Yu, Y. H. Zhou, and X.M. Han J. Phys.: Cond Matter, 15, 5157 (2003)

109. Zhenling Wang, Fuangzhi Li, Zewei Quan, Deyan Kong, Xiaoming Liu, Min Yu, and Jun Lin J. Nanoscience and Nanotechn., 7, 602 (2007).

110. Yeqing Chen, Kyoung Hyun Yang, Wook Sung Park, Kee Byung Moon, Chun Byung Choi, Hyun Jung Jeong, and Ho Kwang Kim J. Alloys and Comp., 511, 123 (2012).

111. Yiguo Su, Liping Li, and Guangshe Li Chem. Mater., 20, 6060 (2008)

112. S. Mahlik, M. Behrendt, M. Grinberg, E. Cavalli, and M. Bettinelli Opt. Mater, 34, $2012(2012)$

113. Haoyi Wu, Yihua Hu, Fengwen Kang, Nana Li, Guifang Ju, Zhongfei Mu, and Zhongfu Yang J. Am. Ceram. Soc., 95, 3214 (2012).

114. Bo Li, Zhennan Gu, Jianhua Lin, and Zeng Mian-Su J. Mater. Sci., 35, 1139 (2000).

115. Bo Li, Zhennan Gu, Jianhua Lin, and Zeng Mian-Su Mat. Res. Bul., 35, 1921 (2000). 
116. M. Machida, S. Murakami, T. Kijima, S. Matsushima, and M. Arai J. Phys. Chem $B, \mathbf{1 0 5}, 3289$ (2001).

117. Meiying Liu, W. You, Z. Lei, T. Takata, K. Domein, and C. Li Chinese J. of Catalysis, 27, 556 (2006).

118. O. Voloshyna, S. V. Neicheva, N. G. Starzhinskiy, I. M. Zenya, S. S. Grindin, V. N. Baumer, and O. Ts. Sidletskiy Mater. Sci. and Engin. B, 178, 1491 (2013).

119. G. Blasse and A. Bril J. Lumin., 3, 109 (1970).

120. M. Nyman, M. A. Rodriguea, L. E. S. Rohwer, J. E. Martin, M. Waller, and F. E. Osterloh Chem. Mater., 21, 4731 (2009).

121. G. C. Bleier, M. Nyman, L. E. S. Rohwer, and M. A. Rodriquez J. Solid State Chem., 184, 3221 (2011).

122. L. L. Noto, S. S. Pitale, M. A. Gusowski, O. M. Ntwaeborwa, J. J. Terblans, and H. C. Swart J. Lumin., 145, 907 (2014).

123. Bo Liu, Kun Han, Xiaolin Liu, Mu Gu, Shiming Huang, Chen Ni, Zeming Qi, and Guobin Zhang Sol. State Commun., 144, 484 (2007).
124. Bo Liu, Mu Gu, Kun Han, Xiaolin Liu, Kun Han, Shiming Huang, Chem Ni, Guobin Zhang, and Zeming Qi Appl. Phys. Lett., 94, 061906 (2009).

125. Huijuan Zhang, Yuhua Wang, and Lechun Xie J. Lumin., 130, 2089 (2010).

126. Xiaolin Liu, Xin Xu, Mu Gu, Lihong Xiao, Kun Han, and Rui Zhang Appl. Surface Science, 253, 4344 (2007)

127. Mu Gu, Liping Zhu, Xiaolin Liu, Shiming Huang, Bo Liu, and Chen Ni J. Alloys Comp., 501, 371 (2010).

128. Mu Gu, Lihong Xiao, Xiaolin Liu, Rui Zhang, Bingjie Liu, and Xin Xu J. Alloys and Compounds, 426, 390 (2006).

129. M. J. J. Lammers and G. Blasse Mater. Res. Bull., 19, 759 (1984).

130. G. Blasse, G. J. Dirksen, L. H. Brixner, and M. K. Crawford J. Alloys and Comp., 209, 1 (1994).

131. Shiwei Chen, Xiaolin Liu, Mu Gu, Chen Ni, Bo Liu, and Shiming Huang J. Lumin., 140, 1 (2013).

132. L. H. Brixner J. Chem. Education, 57, 588 (1980). 